ARTICLE

There are amendments to this paper

https://doi.org/10.1038/s41467-019-13033-4

OPEN

\title{
Elevated aldosterone and blood pressure in a mouse model of familial hyperaldosteronism with CIC-2 mutation
}

\author{
Julia Schewe 1,2,3,4, Eric Seidel (10 1,2,3,4, Sofia Forslund $2,5,6,7$, Lajos Marko 2,5,6,7, Jörg Peters ${ }^{8}$,

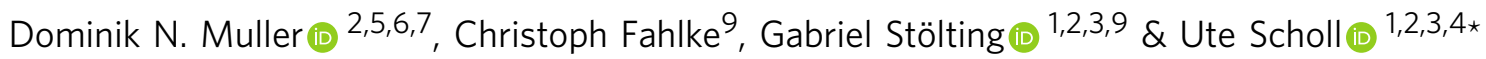

Gain-of-function mutations in the chloride channel CIC-2 were recently described as a cause of familial hyperaldosteronism type II (FH-II). Here, we report the generation of a mouse model carrying a missense mutation homologous to the most common $\mathrm{FH}$-II-associated CLCN2 mutation. In these Clcn2 $2^{\mathrm{R} 180 \mathrm{Q} /+}$ mice, adrenal morphology is normal, but Cyp11b2 expression and plasma aldosterone levels are elevated. Male $\mathrm{Cl} / \mathrm{cn} 2^{\mathrm{R} 180 \mathrm{Q} /+}$ mice have increased aldosterone:renin ratios as well as elevated blood pressure levels. The counterpart knockout model ( $\mathrm{Clcn} 2^{-/-}$), in contrast, requires elevated renin levels to maintain normal aldosterone levels. Adrenal slices of $\mathrm{Clcn} 2^{\mathrm{R} 180 \mathrm{Q} /+}$ mice show increased calcium oscillatory activity. Together, our work provides a knockin mouse model with a mild form of primary aldosteronism, likely due to increased chloride efflux and depolarization. We demonstrate a role of $\mathrm{ClC}-2$ in normal aldosterone production beyond the observed pathophysiology.

\footnotetext{
${ }^{1}$ Charité - Universitätsmedizin Berlin, corporate member of Freie Universität Berlin, Humboldt-Universität zu Berlin Berlin Institute of Health, Department of Nephrology and Medical Intensive Care, Augustenburger Platz 1, Berlin 13353, Germany. ${ }^{2}$ Berlin Institute of Health (BIH), Anna-Louisa-Karsch-Str. 2 , 10178 Berlin, Germany. ${ }^{3}$ Charité-Universitätsmedizin Berlin, corporate member of Freie Universität Berlin, Humboldt-Universität zu Berlin and Berlin Institute of Health, BIH Center for Regenerative Therapies, Föhrer Str. 15, Berlin 13353, Germany. ${ }^{4}$ Department of Nephrology, School of Medicine, Heinrich-HeineUniversität Düsseldorf, Universitätsstraße 1, 40225 Düsseldorf, Germany. ${ }^{5}$ Max Delbruck Center for Molecular Medicine in the Helmholtz Association, Berlin, Germany. ${ }^{6}$ Experimental and Clinical Research Center, a cooperation of Charité-Universitätsmedizin Berlin and Max Delbruck Center for Molecular Medicine, Lindenberger Weg 80, Berlin 13125, Germany. ${ }^{7}$ Charité - Universitätsmedizin Berlin, corporate member of Freie Universität Berlin, HumboldtUniversität zu Berlin and Berlin Institute of Health, Berlin, Germany. ${ }^{8}$ Department of Physiology, Universitätsmedizin Greifswald, Friedrich-Ludwig-Jahn-Str. 15a, 17475 Greifswald, Germany. ${ }^{9}$ Institute of Complex Systems, Zelluläre Biophysik (ICS-4), Forschungszentrum Jülich, 52425 Jülich, Germany. ${ }^{*}$ email: ute. scholl@charite.de
} 
T he adrenal steroid hormone aldosterone is an important regulator of blood pressure and electrolyte homeostasis. In the kidney, its binding to the mineralocorticoid receptor causes increased $\mathrm{Na}^{+}$reabsorption via the apical epithelial sodium channel $\mathrm{ENaC}$ and the basolateral $\mathrm{Na}^{+} / \mathrm{K}^{+}$-ATPase ${ }^{1}$, raising blood pressure. This effect is accompanied by increased $\mathrm{K}^{+}$secretion via the apical ROMK channel ${ }^{2}$, lowering serum potassium levels.

Excessive aldosterone production despite suppressed plasma renin activity and normal or low extracellular potassium levels (relative autonomy) is characteristic of primary aldosteronism (PA), the most common cause of secondary hypertension ${ }^{3,4}$. It accounts for about $6 \%$ of hypertensive patients in primary care and about $10 \%$ in specialized hypertension centers ${ }^{5,6}$. Compared with essential hypertension, $\mathrm{PA}$ is associated with an increased risk of cardiovascular disease 7,8 . Approximately one third of PA cases feature benign, typically unilateral tumors of the adrenal gland (aldosterone-producing adenomas), caused by somatic mutations in ion channels and pumps ${ }^{9-12}$. About two thirds have bilateral adrenal hyperplasia (idiopathic hyperaldosteronism), which may be due to an increased number and size of so-called aldosterone-producing cell clusters that similarly carry somatic mutations ${ }^{13-15}$.

Mendelian forms of PA are rare and often associated with early onset $^{16}$. Known forms are inherited in an autosomal-dominant fashion and include familial hyperaldosteronism type I (FH-I) with mutations in CYP11B2 (aldosterone synthase) ${ }^{17,18}$, FH-III due to mutations in the potassium channel $\mathrm{KCNJ}^{9}{ }^{9,19}$ and FH-IV caused by mutations in the T-type voltage-gated calcium channel CACNA1H 20,21 . Mutations in an L-type calcium channel (CAC$N A 1 D$ ) that is also expressed in the central nervous system are found in a syndrome of PA, seizures, and neurologic abnormalities ${ }^{10}$.

Recently, mutations in the chloride channel ClC-2 encoded by the $C L C N 2$ gene that is expressed in the zona glomerulosa were identified as cause of $\mathrm{FH}-\mathrm{II}^{22,23}$. This syndrome had initially been described in an extended Australian kindred in $1992^{24}$. By exome sequencing of this kindred, we identified a heterozygous CLCN2 mutation (p.Arg172Gln, located at the cytoplasmic end of transmembrane helix C) that was present in eight subjects ${ }^{22}$; incomplete penetrance was observed. In three additional unrelated kindreds with PA, the identical p.Arg172Gln was identified. Further families showed mutations located in the $\mathrm{N}$-terminus (p. Met22Lys, p.Tyr26Asn), C-terminus (p.Ser865A), or the cytoplasmic interface of transmembrane helix K (p.Lys362del) ${ }^{22}$. In an independent study, Fernandes-Rosa and colleagues identified a single case with a de novo N-terminal p.Gly24Asp mutation ${ }^{23}$. By electrophysiology in transfected mammalian cells or Xenopus oocytes, all mutations were shown to cause gain of channel function; mutant channels also led to increased aldosterone production when expressed in an adrenocortical cancer cell line ${ }^{22,23}$. The underlying pathophysiology of PA due to CLCN2 mutations was inferred to be increased chloride conductance of glomerulosa cells (which have high intracellular chloride concentrations), depolarization, activation of voltage-gated calcium channels, calcium influx, increased expression of aldosterone synthase and $\mathrm{PA}^{22,23}$. Most recently, a somatic CLCN2 mutation was found in a single aldosterone-producing adenoma ${ }^{25}$.

Mutations in adrenal ion channels appear to differ in their ability to cause increased proliferation. KCNJ5 mutations that are found in aldosterone-producing adenomas are typically associated with massive bilateral adrenal hyperplasia when present in the germline, requiring bilateral adrenalectomy ${ }^{9,19,26}$. In contrast, germline mutations in the CACNA1H gene are associated with only microscopic glomerulosa hyperplasia ${ }^{20}$. Some subjects with CLCN2 mutations showed bulky adrenal glands or a small adrenal nodule upon computed tomography, but in other cases, adrenal imaging was unremarkable ${ }^{22}$, raising the question whether these mutations affect glomerulosa size in vivo and are responsible for proliferation in aldosterone-producing tumors.

Besides the identification of CLCN2 mutations in PA, very little has been known about any role of anion channels in zona glomerulosa (patho)physiology 27,28. To investigate signaling pathways involved in PA and hypertension due to ClC-2 mutations, we here generate and characterize a mouse model carrying a heterozygous $\mathrm{Clcn} 2$ mutation at the position homologous to the most common mutation in humans (p.Arg172Gln). We study the effect of increased anion permeability on intracellular calcium, a known determinant of glomerulosa aldosterone production ${ }^{27}$.

Here we show that $C l c n 2^{\mathrm{R} 180 \mathrm{Q} /+}$ mice have elevated $C y p 11 b 2$ expression and plasma aldosterone levels. Aldosterone:renin ratios are elevated in male mice, and blood pressure is slightly elevated, consistent with mild PA. The cellular correlate of these findings is an increased calcium oscillatory activity in adrenal glomerulosa cells. These results, combined with the finding of elevated renin levels in $\mathrm{Clcn}^{-/-}$mice, point to an important role of ClC-2 in adrenal physiology and disease.

\section{Results}

Generation of $C l c n 2^{\mathrm{R} 180 \mathrm{Q} /+}$ mice. By sequence alignment, we identified Arg1 180 in the mouse ClC-2 protein (NP_034030) as the residue homologous to human Arg172 that is commonly mutated in $\mathrm{FH}-\mathrm{II}^{22}$. Mouse Arg180 is located in a highly conserved protein region and is encoded by CGG as in humans (Fig. 1a). We introduced a point mutation homologous to human Arg172Gln 22 (chr16:20,712,754C > T (m38); p.Arg180Gln (NP_034030)) on exon 5 of the mouse Clcn2 gene by using CRISPR/Cas9-based genome editing (Fig. 1b, see Methods). Because FH-II is an autosomal dominant disease with heterozygous mutations in humans, mice with the heterozygous p.Arg180Gln mutation $\left(\mathrm{Clcn} 2^{\mathrm{R} 180 \mathrm{Q} /+}\right.$, Fig. 1c, d) were used for further characterization.

Both male and female $C l c n 2^{\mathrm{R} 180 \mathrm{Q} /+}$ mice were viable and fertile, and no obvious changes in morphology or behavior were seen. Compared to C57BL/6N mice, no differences in litter size, mortality rate until the age of 3 weeks or sex distribution among litters were seen (Supplementary Fig. 1a-c). When Clcn2 $2^{\mathrm{R} 180 \mathrm{Q} /+}$ mice were mated with WT mice, about half of surviving offspring were $C l c n 2^{\mathrm{R} 180 \mathrm{Q} /+}$ (Supplementary Fig. 1d).

Whereas $\mathrm{Clcn} 2^{-1-}$ mice showed white matter vacuolization and testicular degeneration as previously reported ${ }^{29,30}$, brain and testis morphology were unremarkable in $\mathrm{Clcn} 2^{\mathrm{R} 180 \mathrm{Q} /+}$ mice (Supplementary Fig. 2).

Clcn2 $2^{\mathrm{R} 180 \mathrm{Q} /+}$ mice show no zona glomerulosa hyperplasia. Sanger sequencing of adrenal cDNA confirmed expression of the mutant allele in the adrenal glands of $C l c n 2^{\mathrm{R} 180 \mathrm{Q} /+}$ mice (Fig. 1d). Total adrenal weight was not significantly different in $C l c n 2^{\mathrm{R} 180 \mathrm{Q} /+}$ mice compared to controls (Fig. 2a). Similarly, by quantitative realtime PCR, overall expression levels of Clcn2 in adrenal gland did not differ between $\mathrm{Clcn} 2^{\mathrm{R} 180 \mathrm{Q} /+}$ mice and controls (Fig. 2b), and there was no sex dimorphism in Clcn2 expression (Fig. 2c). H\&E staining showed normal adrenal zonation and morphology in $C l c n 2^{\mathrm{R} 180 \mathrm{Q} /+}$ mice (Fig. 2d, e). Qualitative assessment of Cyp $11 b 2$ expression and zona glomerulosa morphology using in situ hybridization revealed no evidence of nodular glomerulosa hyperplasia or formation of aldosterone-producing adenomas in $C l c n 2^{\mathrm{R} 180 \mathrm{Q} /+}$ mice (Fig. 3a, b).

$C l c n 2^{\mathrm{R} 180 \mathrm{Q} /+}$ mice have elevated aldosterone and Cyp11b2. Plasma aldosterone levels were significantly increased (356.3 \pm $23.96 \mathrm{pg} \mathrm{ml}^{-1}$ in $\mathrm{Clcn} 2^{\mathrm{R} 180 \mathrm{Q} /+}$ mice versus $242.5 \pm 17.57 \mathrm{pg} \mathrm{ml}^{-1}$ 
a H. sapiens: CAGGCTGTCGGCTCTGGCATCCCTGAGATGAAGACCATCTT GCGGGAGTGGTGCTGAAAGAATACCTCACACTCAAGACCTTTATA musculus: CAGGCTGTCGGGTCTGGCATCCCCGAAATGAAAACCATCCTTCGGGGAGTGGTGCTGAAAGAATACCTCACCCTCAAGACCTTTGTA $\begin{array}{llllllllllllllllllllllllllllllll}\text { H. sapiens: } & \mathrm{Q} & \mathrm{A} & \mathrm{V} & \mathrm{G} & \mathrm{S} & \mathrm{G} & \mathrm{I} & \mathrm{P} & \mathrm{E} & \mathrm{M} & \mathrm{K} & \mathrm{T} & \mathrm{I} & \mathrm{L} & \mathrm{R} & \mathrm{G} & \mathrm{V} & \mathrm{V} & \mathrm{L} & \mathrm{K} & \mathrm{E} & \mathrm{Y} & \mathrm{L} & \mathrm{T} & \mathrm{L} & \mathrm{K} & \mathrm{T} & \mathrm{F} & \mathrm{I} \\ \text { M. musculus: } & \mathrm{Q} & \mathrm{A} & \mathrm{V} & \mathrm{G} & \mathrm{S} & \mathrm{G} & \mathrm{I} & \mathrm{P} & \mathrm{E} & \mathrm{M} & \mathrm{K} & \mathrm{T} & \mathrm{I} & \mathrm{L} & \mathrm{R} & \mathrm{G} & \mathrm{V} & \mathrm{V} & \mathrm{L} & \mathrm{K} & \mathrm{E} & \mathrm{Y} & \mathrm{L} & \mathrm{T} & \mathrm{L} & \mathrm{K} & \mathrm{T} & \mathrm{F} & \mathrm{V}\end{array}$

b

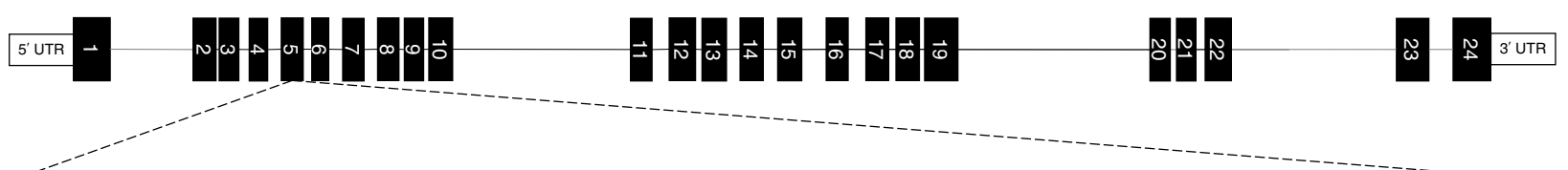

Donor oligo sequence - R1800:

5'ATGCTCCTGGGAACATGTATCTCTGCAGGGTCTGGCATCCCCGAAATGAAAACCATCCTTCAGGGAGTGGTGCTGAAAGAATACCTCACCCTCAAGACCTTTGTAGCTAAGGTCATTGGGCTA-3 Wild-type sequence exon 5:

5'-ATGCTCCTGGGACATGTATCTCTGCAGGGTCTGGCATCCCCGAATGAAA CCATCCTTCGGGGAGTGTGCTGAAGAATACCTCACCCTCAAGACCTTTGTAGCTAAGGTCATTGGGCTA-3 3'-GGTAGGAAGCCCCTCACCACGAC-5

C

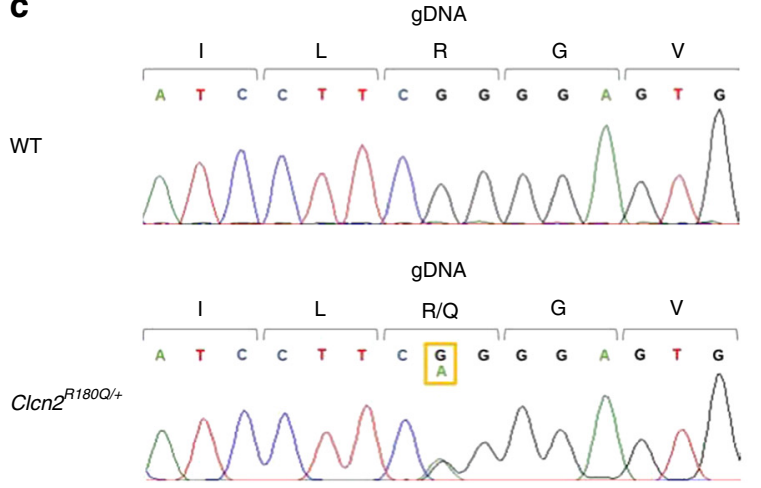

d

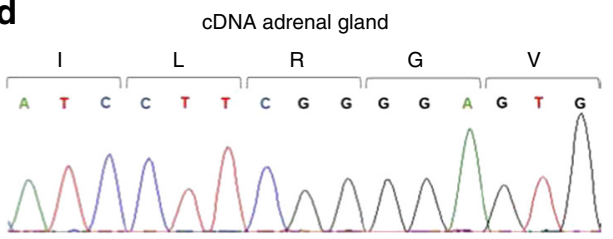

cDNA adrenal gland

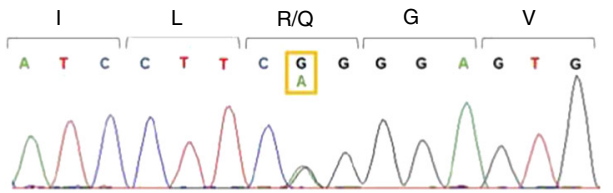

Fig. 1 Generation of a heterozygous Clcn2 $2^{\mathrm{R} 180 \mathrm{Q} /+}$ mouse model. a Alignment of human and mouse protein and genomic sequence surrounding human Arg172 that is commonly mutated in FH-II. b Representation of the mouse Clcn2 locus with the targeted codon on exon 5 . Sequence of gRNA to target the Cas 9 nuclease to exon 5 of the mouse Clcn2 gene is shown below the wildtype sequence. The PAM is underlined. The mutation is introduced by homologydirected repair using a donor oligonucleotide (oligo), with the mutant codon shown in bold letters. c Sanger sequences of a Clcn2 ${ }^{\mathrm{R} 180 \mathrm{Q} /+}$ mouse and a WT control. d Sanger sequences of adrenal cDNA from a Clcn2 R180Q/+ mouse and a WT control. gDNA, genomic DNA

in WT mice, mean $\pm \mathrm{SEM}, \quad P<0.0001$; one-way ANOVA, Sidak's multiple comparisons test (MCP)) (Fig. 4a, Table 1). Aldosterone levels were similarly upregulated in female (WT: 267.4 \pm $22.63 \mathrm{pg} \mathrm{ml}^{-1} ; \mathrm{Clcn}^{\mathrm{R} 180 \mathrm{Q} /+}: 361.5 \pm 28.98 \mathrm{pg} \mathrm{ml}^{-1}$; mean \pm SEM; $P$ $=0.0323$; one-way ANOVA, Bonferroni's MCP) and male mice (WT: $\quad 209.8 \pm 26.29 \mathrm{pg} \mathrm{ml}^{-1} ; \quad C l c n 2^{\mathrm{R} 180 \mathrm{Q} /+}: \quad 347 \pm 43.61 \mathrm{pg} \mathrm{ml}^{-1}$; mean \pm SEM; $P=0.0098 ; \quad$ one-way ANOVA, Bonferroni's MCP) (Fig. 4b, Table 1). Accordingly, Cyp11b2 expression was 1.47 \pm 0.10 -fold higher (mean $\pm \mathrm{SEM}$ ) in $C l c n 2^{\mathrm{R} 180 \mathrm{Q} /+}$ mice than in $\mathrm{WT}$ mice $(P=0.0431$; one-way ANOVA, Sidak's MCP of logtransformed fold change) (Fig. 4c) by real-time PCR. In subgroup analysis, this effect was only seen in male, but not in female animals (Fig. 4e).

In humans with PA and hypertension, renin levels are typically suppressed, contributing to an elevated aldosterone:renin ratio $(\mathrm{ARR})^{4}$. PRC was unchanged between WT and $C l c n 2^{\mathrm{R} 180 \mathrm{Q} /+}$ mice, even in male and female subgroups (Fig. 4f, g, Table 1, see Discussion). Whereas many mouse strains have two renin genes, $\mathrm{C} 57 \mathrm{BL} / 6$ only has $\operatorname{Ren} 1^{31}$. We thus examined relative renal expression levels of the Ren 1 gene in the kidney by quantitative real-time PCR. No significant change in Ren 1 expression was seen in the entire $\mathrm{Clcn} 2^{\mathrm{R} 180 \mathrm{Q} /+}$ group $(1.16 \pm 0.14$-fold of WT, mean \pm SEM, $P=0.9812$; one-way ANOVA, Sidak's MCP) (Fig. 4h), but subgroup analysis showed suppression of Ren 1 expression in males (Fig. 4j).

Next, we calculated ARR from plasma aldosterone concentrations and PRC levels (Fig. 5a, b). There was a non-significant trend towards higher ARR levels in $C l c n 2^{\mathrm{R} 180 \mathrm{Q} /+}$ mice (Fig. 5a) $(0.40 \pm$ $0.05 \mathrm{pg} \mathrm{ml}^{-1}$ : $\mathrm{ng} \mathrm{ml}^{-1} \mathrm{~h}^{-1}$ vs. $0.25 \pm 0.03 \mathrm{pg} \mathrm{ml}^{-1}: \mathrm{ng} \mathrm{ml}^{-1} \mathrm{~h}^{-1}$ in
WT mice; mean \pm SEM; $P=0.0511$; Mann-Whitney test). Subgroup analysis in male and female mice demonstrated significantly increased ARR in male Clcn $2^{\mathrm{R} 180 \mathrm{Q} /+}$ mice only (Fig. 5b) $(0.59 \pm$ $0.12 \mathrm{pg} \mathrm{ml}^{-1}$ : $\mathrm{ng} \mathrm{ml}^{-1} \mathrm{~h}^{-1}$ vs. $0.26 \pm 0.04 \mathrm{pg} \mathrm{ml}^{-1}: \mathrm{ng} \mathrm{ml}^{-1} \mathrm{~h}^{-1}$ in WT mice; mean \pm SEM; $P=0.001$; one-way ANOVA, Bonferroni's MCP; see Discussion). Analogous to this ARR, we calculated a Cyp11b2:Ren 1 expression ratio (Fig. 5c, d). There was no significant change in Cyp11b2:Ren 1 expression ratios in the entire cohort of $\mathrm{Clcn} 2^{\mathrm{R} 180 \mathrm{Q} /+}$ mice (Fig. 5 c) $(1.67 \pm 0.23$ vs. $1.62 \pm$ 0.40 in WT mice, mean \pm SEM, $P=0.6338$; Kruskal-Wallis test, Dunn's MCP), but subgroup analysis showed a significant increase in male $C l c n 2^{\mathrm{R} 180 \mathrm{Q} /+}$ mice only (Fig. $\left.5 \mathrm{~d}\right)(4.40 \pm 0.85$ vs. $2.00 \pm 0.70$ in WT mice, mean $\pm \mathrm{SEM}, \quad P=0.0039$; Kruskal-Wallis test, Dunn's MCP). By quantitative real-time PCR, expression levels of renal aldosterone targets (Slc12a3, encoding the thiazide-sensitive carrier $\mathrm{NCCT}^{32}$, and Sgk1, encoding serum and glucocorticoid-regulated kinase 1, upstream of the epithelial sodium channel $\mathrm{ENaC}$ and the potassium channel $\mathrm{ROMK})^{33}$ were not significantly elevated in $C l c n 2^{\mathrm{R} 180 \mathrm{Q} /+}$ mice compared to WT (Supplementary Fig. 3).

Clcn $2^{\mathrm{R} 180 \mathrm{Q} /+}$ mice show decreased urinary sodium and chloride. The majority of patients with PA do not have hypokalemia $^{4}$, and many patients with FH-II are similarly normokalemic $^{22}$. We determined plasma and spot urinary electrolytes (potassium, sodium, chloride) in $C l c n 2^{\mathrm{R} 180 \mathrm{Q} /+}$ mice and $\mathrm{WT}$ controls. Whereas no changes in plasma electrolytes or urinary potassium levels were observed (Fig. 6a-d), urinary sodium $\left(82.02 \pm 6.58 \mathrm{mmol}^{-1}\right.$ vs. $129.5 \pm 15.31 \mathrm{mmol}^{-1}$ in WT; mean 
a

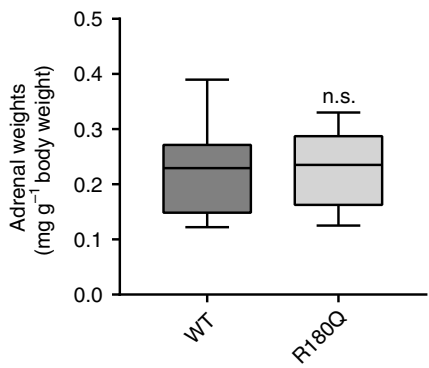

b

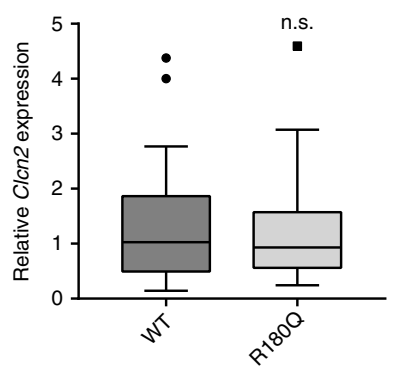

C

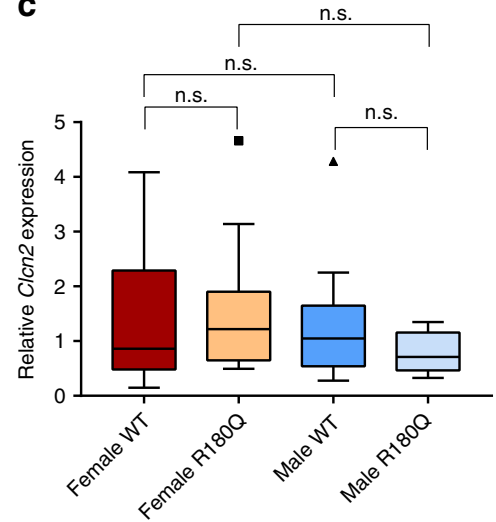

d

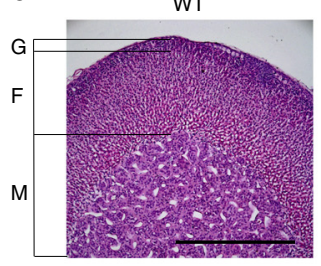

$\mathrm{R} 180 \mathrm{Q}$

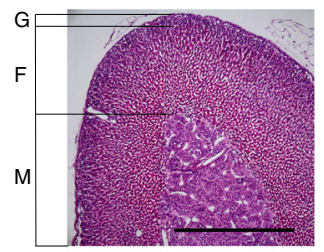

e

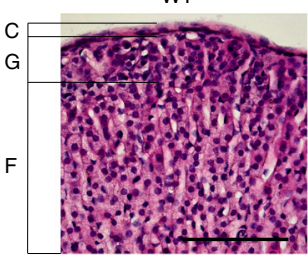

R180Q

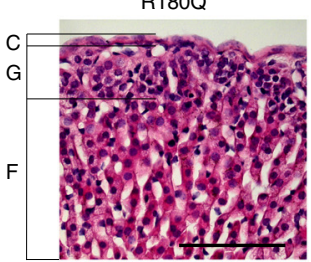

Fig. 2 Adrenal phenotype of $C l c n 2^{\mathrm{R} 180 \mathrm{Q} /+}$ mice. a Adrenal weights (normalized to body weight) are not significantly different between WT ( $N=31 ; 0.22 \pm$ $\left.0.01 \mathrm{mg} \mathrm{g}^{-1}\right)$ and $\mathrm{Clcn} 2^{\mathrm{R} 180 \mathrm{Q} /+}$ mice $\left(N=30 ; 0.22 \pm 0.01 \mathrm{mg} \mathrm{g}^{-1} ; P=0.599 ;\right.$ Mann-Whitney test $)$. b Adrenal expression of Clcn2 is unchanged in $\mathrm{Clcn} 2^{\mathrm{R} 180 \mathrm{Q} /+}$ compared to WT $\left(\mathrm{Clcn} 2^{\mathrm{R} 180 \mathrm{Q} /+}: \mathrm{N}=25,1.24 \pm 0.2, \mathrm{WT}: N=32,1.34 \pm 0.19 ; P=0.8235\right.$; Unpaired $t$ test of log-transformed fold change; $t=$ $0.2241 ; \mathrm{df}=55)$. c Sex specific Clcn2 expression does not differ between WT and Clcn2 $2^{\mathrm{R} 180 \mathrm{Q} /+}$ (female WT: $N=17,1.4 \pm 0.27 ;$ female $C l c n 2^{\mathrm{R} 180 \mathrm{Q} /+}: \mathrm{N}=$ $18,1.5 \pm 0.26$, vs. female WT $P=0.8999$; male WT: $N=15,1.28 \pm 0.26$, vs. female WT $P>0.9999$; male $C / c n 2^{R 180 Q /+:} N=7,0.79 \pm 0.14$, vs. female $\mathrm{Clcn2} \mathrm{R}^{\mathrm{R} 180 \mathrm{Q} /+} P=0.3700$, vs. male WT $P=0.7845$; one-way ANOVA including Sidak's MCP of log-transformed fold change; $F=1.492 ; \mathrm{df}=53$ ). All data (a-c) are specified as mean \pm SEM in the legend; box plots are shown in the figure (box, interquartile range; whiskers, 1.5 times the interquartile range; line, median; dots, outliers); $N$ values are biologically independent animals. n.s., p $>0.05$ d, e H\&E stainings of adrenal sections show unaltered morphology of Clcn2 $2^{\mathrm{R} 180 \mathrm{Q} /+}$ compared to WT (nine mice each, representative images). C capsule, G glomerulosa, F fasciculata, M medulla (scale bars: (d) $500 \mu$ m; (e) $100 \mu \mathrm{m}$ )

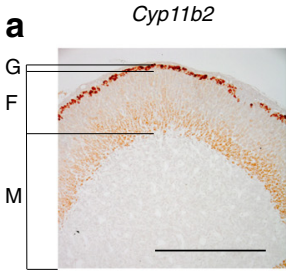

b

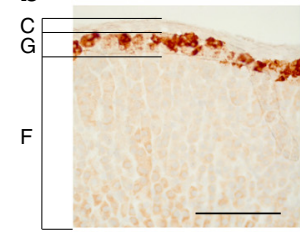

WT
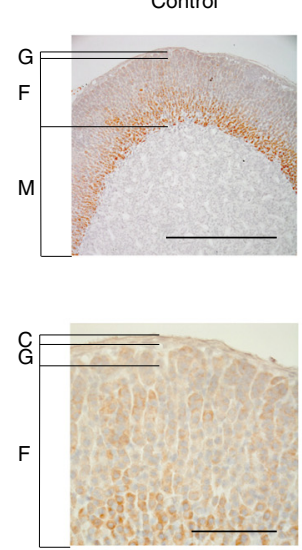

R180Q

Cyp11b2
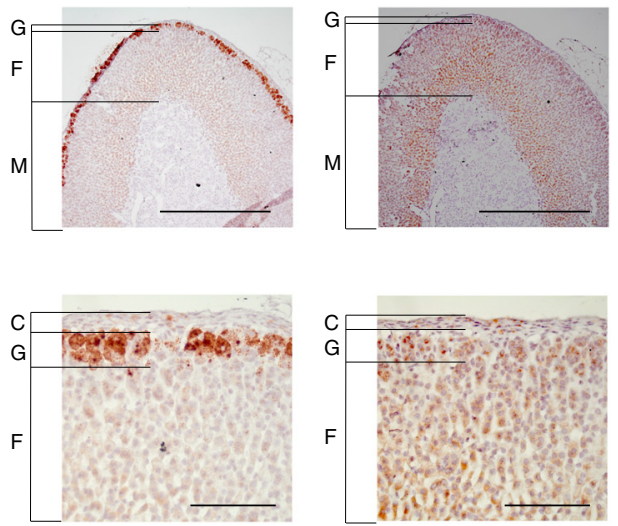

Fig. 3 Cyp11b2 expression in adrenal glands of $\mathrm{Clcn} 2^{\mathrm{R} 180 \mathrm{Q} /+}$ mice. Adrenal sections of WT and Clcn2 $180 \mathrm{Q} /+$ mice (one of six stainings each is shown. C capsule, G glomerulosa, F fasciculata, M medulla) stained by in situ hybridization for Cyp11b2, with corresponding negative controls (see Methods). (a) scale bar, $500 \mu \mathrm{m}$. (b) scale bar, $100 \mu \mathrm{m}$

\pm SEM; $P=0.0032$; one-way ANOVA, Sidak's MCP, Fig. 6e) and chloride levels $\left(161.9 \pm 10.97 \mathrm{mmoll}^{-1}\right.$ vs. $211.3 \pm$ $12.65 \mathrm{mmol} \mathrm{l}^{-1}$ in WT; mean \pm SEM; $P=0.0148$; one-way ANOVA, Sidak's MCP, Fig. 6f) were lower in Clcn2 $2^{\mathrm{R} 180 \mathrm{Q} /+}$ mice (Fig. 6b), suggesting increased retention, lower salt intake or a more dilute urine. Interestingly, in subgroup analysis, this effect was only significant in female, but not male mice.
Clcn $2^{\mathrm{R} 180 \mathrm{Q} /+}$ mice have slightly elevated blood pressure. To assess whether $C l c n 2^{\mathrm{R} 180 \mathrm{Q} /+}$ mice develop hypertension, we measured blood pressure of unanaesthetized 3-month-old male mice by telemetry, using catheters implanted in the carotid artery (see Methods). Systolic and diastolic blood pressures as well as mean arterial pressure (MAP) of $\mathrm{Clcn}^{\mathrm{R} 180 \mathrm{Q} /+}$ mice were slightly but significantly increased when compared to WT 

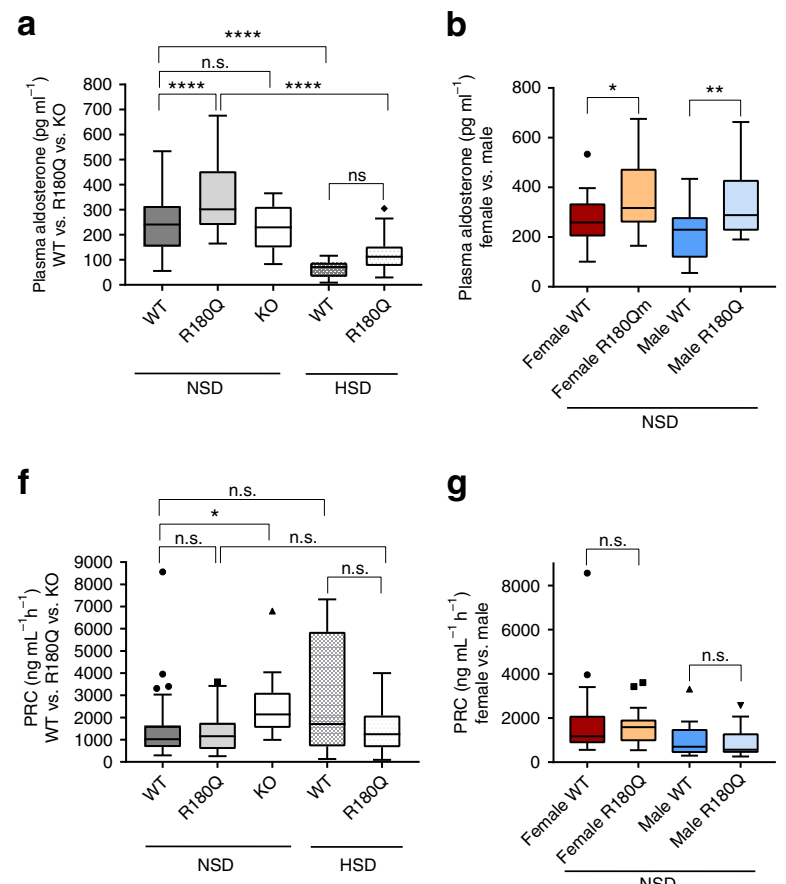

g

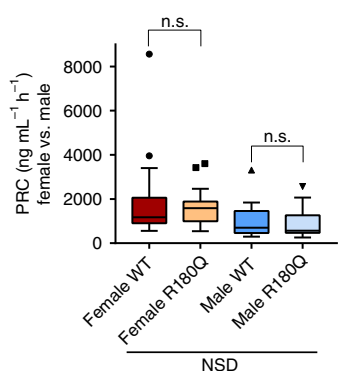

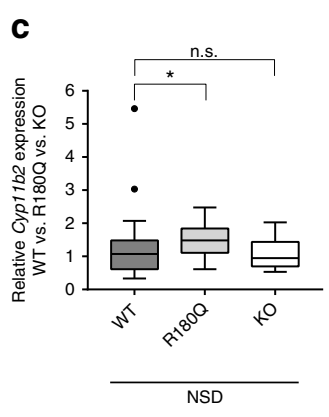
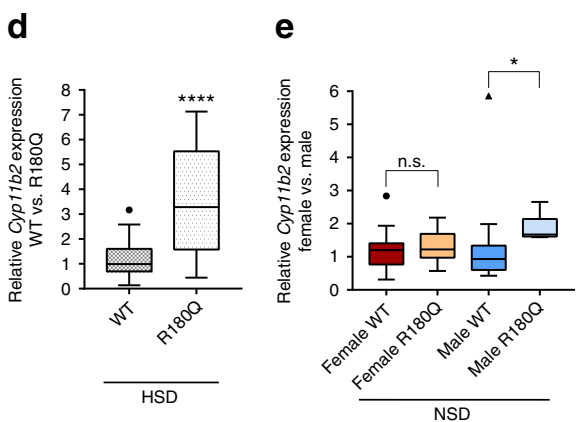

h

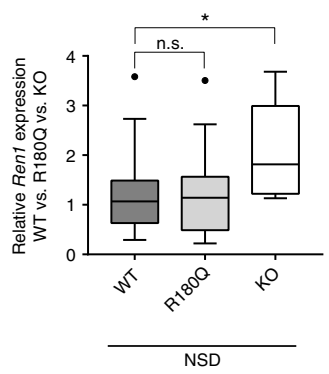

i

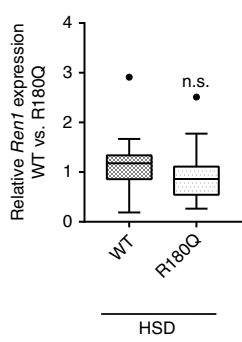

j

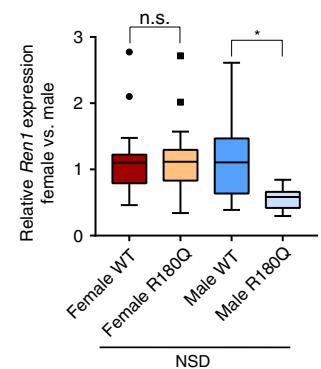

Fig. $4 \mathrm{Clcn} 2^{\mathrm{R} 180 \mathrm{Q} /+}$ mice have elevated Cyp11b2 expression and plasma aldosterone levels. a, c, d Plasma aldosterone $\left(\mathrm{WT}: N=37 ; \mathrm{Clcn} 2^{\mathrm{R} 180 \mathrm{Q} /+}: \mathrm{N}=36\right.$; $P<0.0001 ;$ one-way ANOVA, Sidak's MCP; $F=4.161 ; \mathrm{df}=120)$ and Cyp11b2 expression (WT: $N=32,1.23 \pm 0.17 ; C l \mathrm{cn} 2^{\mathrm{R} 180 \mathrm{Q} /+:} \mathrm{N}=25,1.47 \pm 0.1 ; P=$ 0.0431 ; one-way ANOVA, Sidak's MCP of log-transformed fold change; $F=2.907 ; \mathrm{df}=63$ ) are significantly increased in $\mathrm{Clcn2} 2^{\mathrm{R} 180 \mathrm{Q} /+}$ mice. $\mathrm{Clcn2}-/-$ mice have unchanged plasma aldosterone $(N=10 ; P=0.999 ; F=4.313 ; \mathrm{df}=118)$ and Cyp11b2 expression $(N=10 ; P=0.9959 ;$ both one-way ANOVA including Sidak's MCP; $F=2.907 ; \mathrm{df}=63$ ). HSD leads to suppressed aldosterone levels in WT (WT: $N=37 ; \mathrm{HSD}-\mathrm{WT}: N=19 ; P<0.0001)$ and $\mathrm{Clcn2} 2^{\mathrm{R} 180 \mathrm{Q} /+}\left(\mathrm{Clcn2} 2^{\mathrm{R} 180 \mathrm{Q} /+}: \mathrm{N}=36 ; \mathrm{HSD}-\mathrm{Clcn} 2^{\mathrm{R} 180 \mathrm{Q} /+}: \mathrm{N}=23 ; P<0.0001 ;\right.$ both one-way ANOVA, Sidak's MCP; $\left.F=4.313 ; \mathrm{df}=118\right)$. Cyp11b2 expression is upregulated in Clcn2 $2^{\mathrm{R} 180 \mathrm{Q} /+}$ compared to WT (HSD-WT: $N=24 ; \mathrm{HSD}-\mathrm{Clcn2} 2^{\mathrm{R} 180 \mathrm{Q} /+}: \mathrm{N}=27 ; P<0.0001 ;$ Mann-Whitney test). b, e Plasma aldosterone is elevated in females (WT: $\left.N=21 ; C l c n 2^{\mathrm{R} 180 \mathrm{Q} /+}: N=23 ; P=0.0323 ; \mathrm{df}=69\right)$ and males (WT: $N=16 ; C l c n 2^{\mathrm{R} 180 \mathrm{Q} /+}: N=13 ; P=0.0098 ;$ both one-way ANOVA, Bonferroni's MCP; $F=5.589 ; \mathrm{df}=69), C y p 11 b 2$ expression is upregulated only in male $C l c n 2^{\mathrm{R} 180 \mathrm{Q} /}+\left(\mathrm{WT}: N=15 ; C l \mathrm{cn} 2^{\mathrm{R} 180 \mathrm{Q} /+}: \mathrm{N}=7 ; P=\right.$ 0.0275 ; one-way ANOVA including Sidak's MCP; $F=1.782 ; \mathrm{df}=53) . \mathbf{f}, \mathbf{h}, \mathbf{i}$ PRC is unchanged (WT: $N=37,1474 \pm 245.3 \mathrm{ng} \mathrm{ml} l^{-1} \mathrm{~h}^{-1}, \mathrm{Clcn} 2^{\mathrm{R} 180 \mathrm{Q} /+}: \mathrm{N}=$ $36,1334 \pm 138.7 \mathrm{ng} \mathrm{ml}^{-1} \mathrm{~h}^{-1}, P>0.9999 ; \mathrm{HSD}-\mathrm{WT}: \mathrm{N}=19,2830 \pm 590.3 \mathrm{ng} \mathrm{ml}^{-1} \mathrm{~h}^{-1} ; \mathrm{HSD}-\mathrm{Clcn2} 2^{\mathrm{R} 180 \mathrm{Q} /+}$ : $N=23,1522 \pm 218.4 \mathrm{ng} \mathrm{ml}^{-1} \mathrm{~h}^{-1}, \mathrm{P}>0.9999$; both Kruskal-Wallis test, Dunn's MCP). Ren1 expression is unchanged (WT: $N=32,1.17 \pm 0.12 ; C l c n 2$ R180Q/+: $N=27,1.16 \pm 0.14 ; P=0.9812 ;$ one-way ANOVA including Sidak's MCP; $F=0.7894 ; \mathrm{df}=63 ; \mathrm{HSD}-\mathrm{WT}: N=24,1.26 \pm 0.15 ; \mathrm{HSD}-\mathrm{Clcn} 2^{\mathrm{R} 180 \mathrm{Q} /+}: \mathrm{N}=27,1.462 \pm 0.23 ; P=0.9813 ; \mathrm{Mann}-\mathrm{Whitney}$ test). In Clcn2 ${ }^{-/-}$, the expression of Ren1 (WT: $N=32,1.17 \pm 0.12 ; C l c n 2^{-/-}: N=10,2.1 \pm 0.32 ; P=0.0125$; one-way ANOVA including Sidak's MCP; $F=$ $0.7894 ; \mathrm{df}=63$ ) and PRC (WT: $N=37,1474 \pm 245.3 \mathrm{ng} \mathrm{ml}^{-1} \mathrm{~h}^{-1} ; C l \mathrm{cn}^{-/-}: N=10,2602 \pm 546.1 \mathrm{ng} \mathrm{ml}^{-1} \mathrm{~h}^{-1} ; P=0.03$; Kruskal-Wallis test, Dunn's MCP) are significantly upregulated compared to WT. g, j Female (WT: $N=21,1839 \pm 392 \mathrm{ng} \mathrm{ml}^{-1} \mathrm{~h}^{-1} ; C_{\mathrm{cm}} 2^{\mathrm{R} 180 \mathrm{Q} /+}: \mathrm{N}=23,1589 \pm 166.3 \mathrm{ng} \mathrm{ml}^{-1} \mathrm{~h}^{-1} ; \mathrm{P}>$ 0.9999;) as well as male mice (WT: $N=16,995.1 \pm 194.7 \mathrm{ng} \mathrm{ml}^{-1} \mathrm{~h}^{-1} ; C_{\mathrm{cnn}} 2^{\mathrm{R} 180 \mathrm{Q} /+}: \mathrm{N}=13,882.6 \pm 198 \mathrm{ng} \mathrm{ml}^{-1} \mathrm{~h}^{-1} ; \mathrm{P}>0.9999 ;$ both Kruskal-Wallis test; Dunn's MCP) show no significant alteration in PRC. Ren1 expression is significantly downregulated in male Clcn2R180Q/ + mice only (WT: $N=15,1.14$ $\pm 0.16 ; C_{l n} 2^{R 180 Q /+}: N=7,0.57 \pm 0.07 ; P=0.0158$; one-way ANOVA including Sidak's MCP; $F=0.6378$; $d f=53$ ). Mean \pm SEM for all data in the legend; box plots (box, interquartile range; whiskers, 1.5 times the interquartile range; line, median; dots, outliers) are shown in the figure; $N$ values are biologically independent animals. NSD, normal salt diet. ${ }^{\star}, p<0.05 ;{ }^{\star \star}, p<0.01 ;{ }^{\star \star \star \star}, p<0.0001 ;$ n.S., $p>0.05$

(systolic, $120.6 \pm 0.1 \mathrm{mmHg}$ versus $116.4 \pm 0.1 \mathrm{mmHg} ; P=0.007$; diastolic, $88.0 \pm 0.1 \mathrm{mmHg}$ versus $84.2 \pm 0.1 \mathrm{mmHg} ; P=0.020$; MAP, $103.8 \pm 0.1$ versus $100.1 \pm 0.1 ; P=0.009$; all mean \pm SEM and Nested-model likelihood ratio comparisons). Heart rate was not significantly changed in $C l c n 2^{\mathrm{R} 180 \mathrm{Q} /+}(507.9 \pm 0.4 \mathrm{BPM}$, mean \pm SEM) versus WT $(495.2 \pm 0.4 \mathrm{BPM} ; P=0.225$; Nestedmodel likelihood ratio comparisons) (Fig. 7).

$C l c n 2^{\mathrm{R} 180 \mathrm{Q} /+}$ mice show an altered high-salt response. Hypertension in states of high aldosterone is salt-dependent ${ }^{34}$, and impaired suppression of aldosterone upon salt loading is diagnostic of PA in humans ${ }^{4}$. We therefore fed $C l c n 2^{\mathrm{R} 180 \mathrm{Q} /+}$ mice and WT controls a high-salt diet (HSD) (1.71\% sodium) for 4 weeks, added $1 \% \mathrm{NaCl}$ to the drinking water, measured plasma aldosterone as well as PRC and harvested adrenal glands and kidneys for RNA extraction. Plasma aldosterone dropped after HSD (Fig. 4a) in both genotypes, whereas PRC showed no significant change (Fig. 4f). We next measured adrenal Cyp11b2 expression and renal Ren 1 expression. This revealed incomplete suppression of relative Cyp11b2 expression in $C l c n 2^{\mathrm{R} 180 \mathrm{Q} /+}$ mice $(2.85 \pm 0.34)$ compared to WT mice $(1.34 \pm 0.23$, mean $\pm \mathrm{SEM}$, $P<0.0001$; Mann-Whitney test) (Fig. 4d).

Aged $C l c n 2^{\mathrm{R} 180 \mathrm{Q} /+}$ mice show no evidence of end-organ damage. To study whether elevated aldosterone levels in $C l c n 2^{\mathrm{R} 180 \mathrm{Q} /+}$ mice are associated with end-organ damage, we harvested kidneys and hearts from 11-month-old mice. H\&E staining (Supplementary Fig. 4), as well as staining for collagen (fibrosis, Supplementary Fig. 5) or macrophages (inflammation, Supplementary Figs. 6, 7) did not reveal qualitative differences between $C l c n 2^{\mathrm{R} 180 \mathrm{Q} /+}$ mice and controls. Aged mice also did not show evidence of adrenal hyperplasia (Supplementary Fig. 4).

Altered glomerulosa calcium signaling in $\mathrm{Clcn} 2^{\mathrm{R} 180 \mathrm{Q} /+}$ mice. Physiological stimuli of glomerulosa aldosterone production such as hyperkalemia and AT-II lead to an increase of the cytosolic 


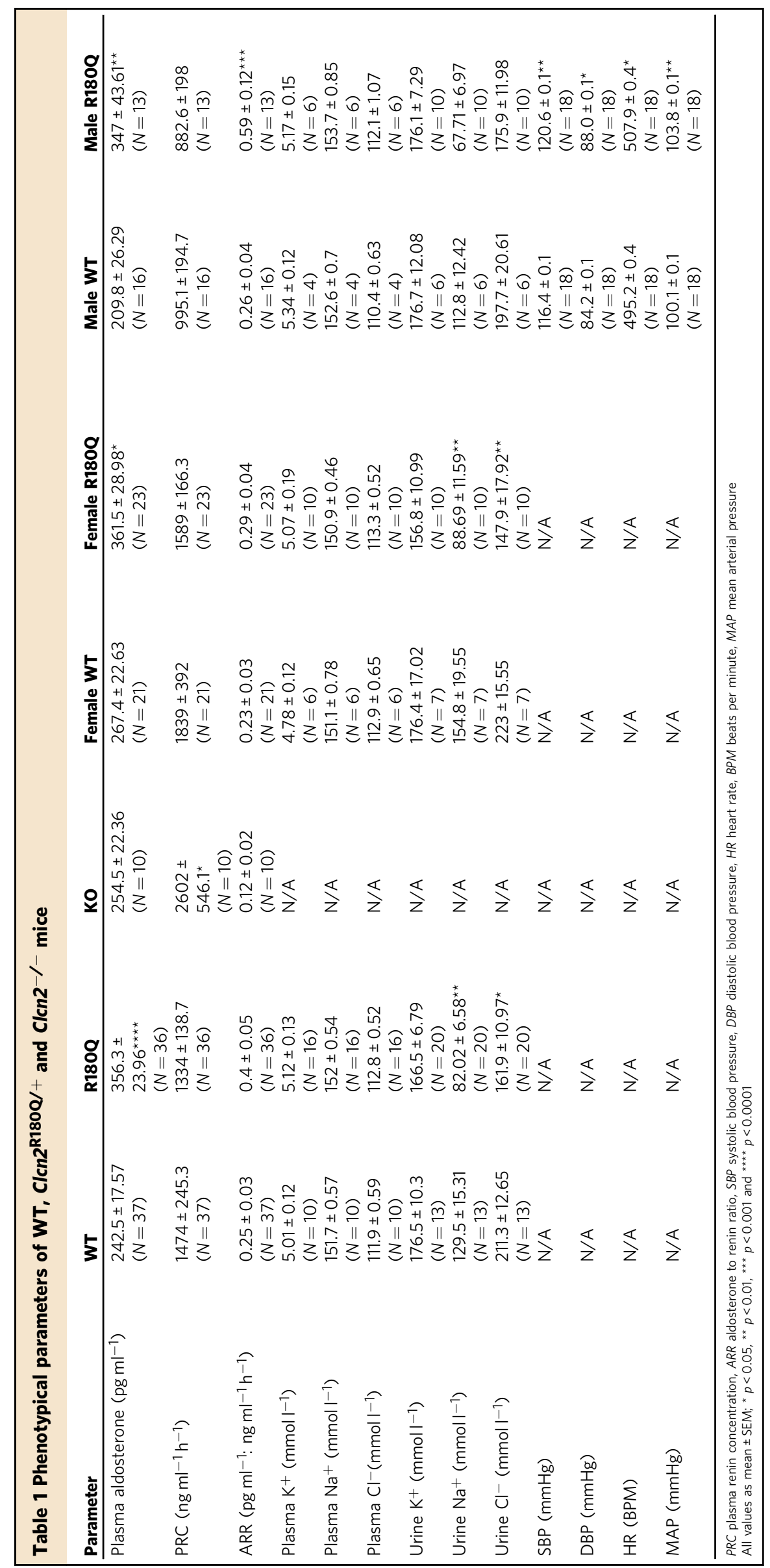



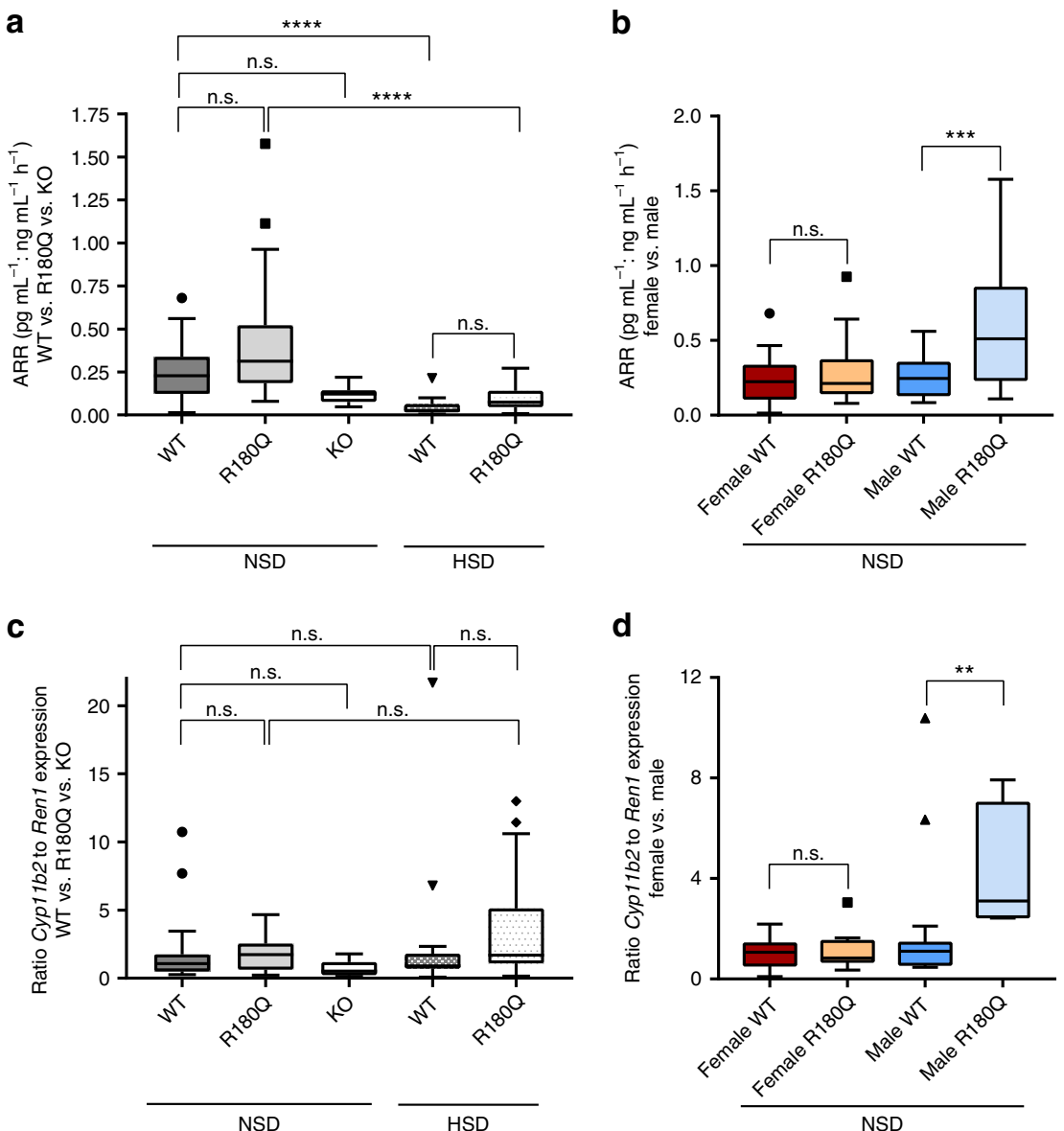

Fig. 5 Male Clcn2 $2^{\mathrm{R} 180 \mathrm{Q} /+}$ mice have elevated aldosterone:renin ratios. a Aldosterone:renin ratios (ARR) were calculated using values of plasma aldosterone levels and PRC. No significant differences were detected for $C l c n 2^{R 180 Q} /+$ mice compared to WT under normal salt (WT: $N=37 ; C l c n 2^{R 180 Q} /+: N=36$; $P=0.5892$ ) as well as after HSD (HSD-WT: $N=19 ; \mathrm{HSD}-\mathrm{Cl}$ cn2 $2^{\mathrm{R} 180 \mathrm{Q} /+}: \mathrm{N}=23 ; P=0.3788$; both Kruskal-Wallis test, Dunn's MCP). In addition, ARR of Clcn2 ${ }^{-/-}$mice was not significantly changed compared to WT (WT: $N=37 ; C l c n 2^{-/-}: N=10 ; P=0.2089 ;$ Kruskal-Wallis test, Dunn's MCP). b Subgroup analysis showed increased ARR levels in male Clcn2R180Q/+ mice compared to WT (WT: $N=16 ; C l c n 2^{R 180 Q /+: ~} N=13 ; P=0.0010 ;$ one-way ANOVA including Bonferroni's MCP; $F=6.896 ; \mathrm{df}=69)$, but not in female mice (WT: $N=21 ; C l \mathrm{cn} 2^{\mathrm{R} 180 \mathrm{Q} /+}: N=23 ; P=0.8346$; one-way ANOVA including Bonferroni's MCP; $F=6.896 ; \mathrm{df}=69)$. c A ratio of Cyp11b2 and Ren1 expression was calculated using fold change. There is no significant difference between Clcn2R180Q/+ and WT mice as well as Clcn2-/- compared to WT (WT: N=32; Clcn2 $2^{\mathrm{R} 180 \mathrm{Q} /+}: \mathrm{N}=25 ; P=0.8622 ; \mathrm{Clcn2} 2^{-/-}: \mathrm{N}=10$, $P=0.6780$; Kruskal-Wallis test, Dunn's MCP). After HSD, the ratio was slightly increased in Clcn2R180Q/+ mice compared to WT (HSD-WT: $N=24$; HSD-Clcn2 $2^{\mathrm{R} 180 \mathrm{Q} /+}: \mathrm{N}=27 ; P=0.0711 ;$ Kruskal-Wallis test, Dunn's MCP). d The ratio was significantly increased in male Clcn2 $2^{\mathrm{R} 180 \mathrm{Q} /+}$ mice compared to WT (WT: $N=15 ; C l c n 2^{R 180 Q /+}: N=7 ; P=0.0039 ;$ Kruskal-Wallis test and Dunn's MCP), but not in female mice (WT: $N=17 ; C l c n 2^{R 180 Q /+}: N=18$; $P>0.9999 ;$ Kruskal-Wallis test and Dunn's MCP). All data are shown in box plots (box, interquartile range; whiskers, 1.5 times the interquartile range; line, median; dots, outliers); $N$ values are biologically independent animals. ${ }^{\star \star}, p<0.01 ;{ }^{\star \star \star}, p<0.001 ;{ }^{* \star \star \star}, p<0.0001 ;$ n.s., $p>0.05$

calcium concentration ${ }^{27}$, and similar mechanisms have been suggested to underlie hyperaldosteronism in subjects with CLCN2 mutations ${ }^{22,23}$. To detect relative changes in intracellular glomerulosa calcium concentrations in $C l c n 2^{\mathrm{R} 180 \mathrm{Q} /+}$ mice and WT controls, we loaded acute adrenal slice preparations with the fluorescent and cell-permeable calcium indicator Calbryte 520 AM (see Methods) and studied cellular responses to changes in extracellular $\mathrm{K}^{+}$and AT-II. In the absence of AT-II, only a negligible number of cells showed calcium spikes in both strains, in agreement with previous reports for WT mice ${ }^{35}$. Increasing [AT-II] to $20 \mathrm{pM}$ in the perfusion solution (similar to levels in healthy humans ${ }^{36} ; 50 \mathrm{pM}$ have been reported in mice ${ }^{37}$ ) resulted in visible activity in some cells, either as single, isolated spikes or as temporally clustered bursts of activity (burst plots in Fig. 8a, b; Supplementary Movies 1 and 2). Raising the concentration of ATII above physiological levels to $1 \mathrm{nM}$ further increased the extent of bursting activity (Fig. 8a, b).
To examine whether calcium signaling in $C l c n 2^{\mathrm{R} 180 \mathrm{Q} /+}$ mice is altered, we assessed the oscillatory activity in individual cells. To account for the potential lack of independence between cells from the same animal, linear mixed modeling was performed as described in Methods. The number of spikes in the absence of AT-II was insufficient for statistical analysis. Mean activity was significantly higher in $C l c n 2^{\mathrm{R} 180 \mathrm{Q} /+}$ mice than in WT mice at $3 \mathrm{mM}\left[\mathrm{K}^{+}\right]$, both for 20 pM AT-II (mean \pm SD Clcn $2^{\mathrm{R} 180 \mathrm{Q} /+}$ vs. WT: $0.0234 \pm$ 0.0478 vs. $0.0038 \pm 0.0130 \mathrm{~s}^{-1}$ cell $^{-1}, \quad \chi 2(1)=5.3413, \quad P=$ $0.0208, N=134 / 134$; likelihood ratio test) and $1 \mathrm{nM}$ AT-II $\left(0.2163 \pm 0.1568\right.$ vs. $0.1247 \pm 0.1114 \mathrm{~s}^{-1}$ cell $^{-1}, \chi^{2}(1)=11.97$, $P=0.0005, N=157 / 134$; likelihood ratio test). This was also the case at additional stimulation with $5 \mathrm{mM}\left[\mathrm{K}^{+}\right]$for $1 \mathrm{nM}$ AT-II $\left(0.3191 \pm 0.2003\right.$ vs. $0.1830 \pm 0.1445 \mathrm{~s}^{-1}$ cell $^{-1}, \chi^{2}(1)=$ 8.3487, $\quad P=0.0039, \quad N=154 / 134$; likelihood ratio test) (Fig. 8c). These results support upregulated calcium signaling 

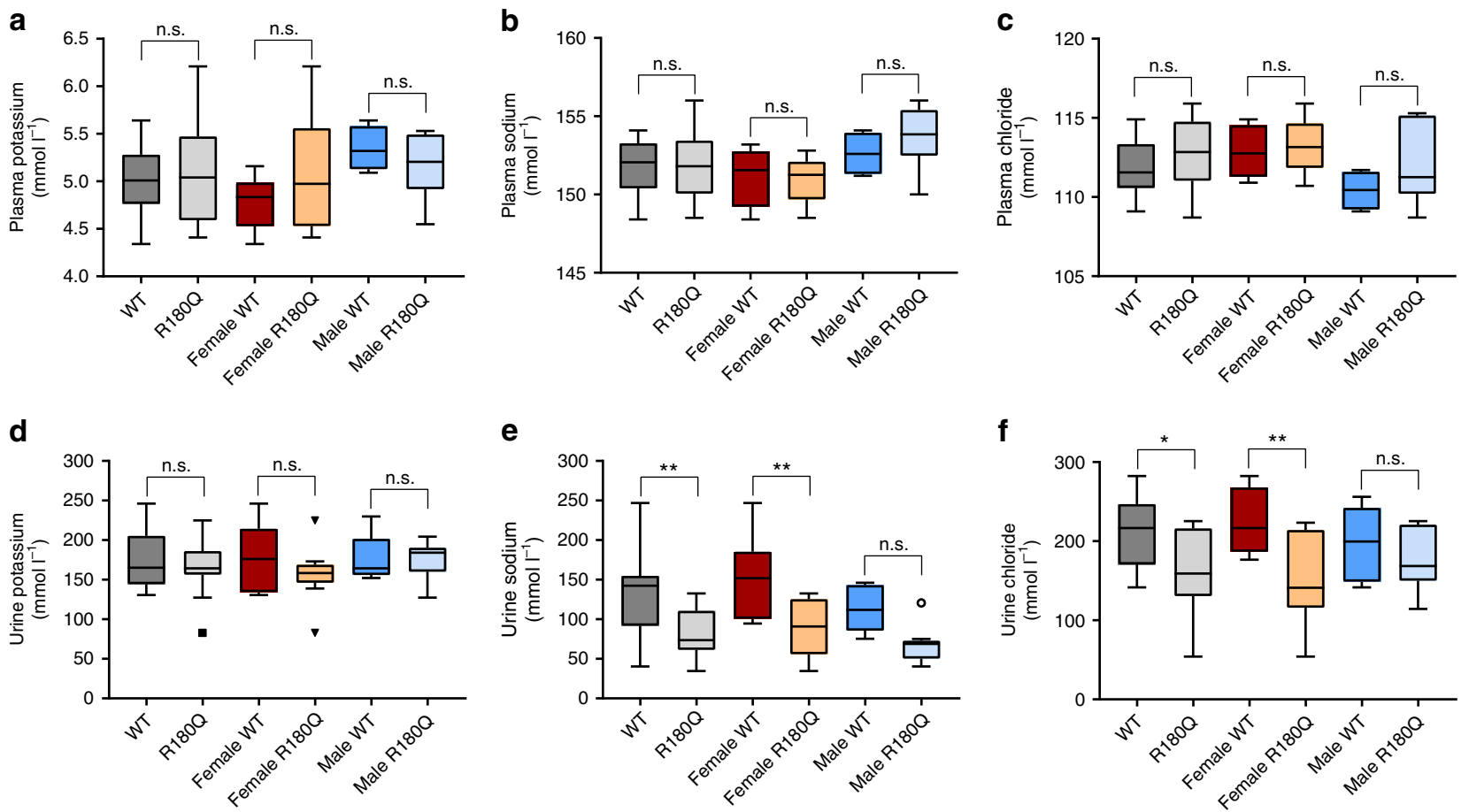

Fig. 6 Plasma and urine electrolyte levels. Plasma levels of potassium (a) (WT: $N=10 ; C l c n 2$ R180Q/+: $N=16 ; P=0.9315 ;$ female WT: $N=6$; female Clcn2R180Q/+: $N=10 ; P=0.5490 ;$ male WT: $N=4 ;$ male Clcn2R180Q/+: $N=6 ; P=0.9161 ;$ one-way ANOVA including Sidak's MCP; $F=1.02 ; \mathrm{df}=46$ ), sodium (b) (WT: $N=10 ; C l c n 2^{\mathrm{R} 180 \mathrm{Q} /+}: N=16 ; P=0.9854$; female WT: $N=6$; female $C l c n 2^{\mathrm{R} 180 \mathrm{Q} /+}: N=10 ; P=0.9956 ;$ male WT: $N=4$; male Clcn2R180Q/+: $N=6 ; P=0.7652 ;$ one-way ANOVA including Sidak's MCP; $F=0.4119 ; \mathrm{df}=46)$ and chloride (c) $\left(\mathrm{WT}: N=10 ; C l c n 2^{\mathrm{R} 180 \mathrm{Q} /+}: \mathrm{N}=16 ; P=\right.$ 0.5559; female WT: $N=6$; female $C l c n 2^{\mathrm{R} 180 \mathrm{Q} /+}: \mathrm{N}=10 ; P=0.9658$; male WT: $N=4$; male Clcn2 $2^{\mathrm{R} 180 \mathrm{Q} /+}$ : $N=6 ; P=0.4857$; one-way ANOVA including Sidak's MCP; $F=0.5725 ; \mathrm{df}=46)$ do not differ between WT and $C / \mathrm{cn} 2^{\mathrm{R} 180 \mathrm{Q} /+}$ mice. Urinary potassium $(\mathbf{d})$ is not changed in $\mathrm{Clcn} 2^{\mathrm{R} 180 \mathrm{Q} /+}+\mathrm{mice}(\mathrm{WT}$ : $N=13 ; C l c n 2^{R 180 Q /+}: N=20 ; P=0.7833$; female WT: $N=7$; female $C l c n 2^{R 180 Q /+}: N=10 ; P=0.5567 ;$ male WT: $N=6 ;$ male $C l c n 2^{R 180 Q} /+: N=10 ; P>$ 0.9999; one-way ANOVA including Sidak's MCP; $F=0.9392 ; \mathrm{df}=60)$. In contrast, urine levels of sodium (e) $\left(\mathrm{WT}: N=13 ; C l \mathrm{cn} 2^{\mathrm{R} 180 \mathrm{Q} /+} \mathrm{i}: \mathrm{N}=20 ; P=\right.$ 0.0032 ; female WT: $N=7$; female $C l c n 2^{\mathrm{R} 180 \mathrm{Q} /+}: N=10 ; P=0.0030$; male $\mathrm{WT}: N=6$; male $C / \mathrm{cn} 2^{\mathrm{R} 180 \mathrm{Q} /+}: N=10 ; P=0.0819$; one-way ANOVA including Sidak's MCP; $F=1.617 ; \mathrm{df}=60)$ and chloride (f) $\left(\mathrm{WT}: N=13 ; C l c n 2^{\mathrm{R} 180 \mathrm{Q} /+}: N=20 ; P=0.0148 ;\right.$ female $\mathrm{WT}: N=7 ;$ female $C l \mathrm{cn} 2^{\mathrm{R} 180 \mathrm{Q} /+}: \mathrm{N}=10 ; P=$ 0.0064; male WT: $N=6$; male Clcn2 $2^{\mathrm{R} 180 \mathrm{Q} /+} \mathrm{N}=10 ; P=0.7609$; one-way ANOVA including Sidak's MCP; $\left.F=0.4131 ; \mathrm{df}=60\right)$ show significant decreases in $\mathrm{Clcn} 2^{\mathrm{R} 180 \mathrm{Q} /+}$ overall and in female mice. All data are shown in box plots (box, interquartile range; whiskers, 1.5 times the interquartile range; line, median; dots, outliers); $N$ values are biologically independent animals. ${ }^{\star}, p<0.05 ;{ }^{\star \star}, p<0.01 ;$ n.S., $p>0.05$

as a major factor in the pathogenesis of elevated aldosterone levels in $C l c n 2^{\mathrm{R} 180 \mathrm{Q} /+}$ mice.

Clcn2 $2^{\mathrm{R} 180 \mathrm{Q} /+}$ increases [AT-II]-dependent calcium bursting. As activity in cells appears to be clustered, we defined bursts of calcium activity based on interspike interval analysis (see Methods). Again, analysis was performed using a linear mixed model to account for potential non-independence of cells from the same animal (see Methods). The number of calcium bursts per second and cell was significantly increased in $\mathrm{Clcn}_{2} 2^{\mathrm{R} 180 \mathrm{Q} /+}$ mice compared to WT at $1 \mathrm{nM}$ AT-II for both, 3 and $5 \mathrm{mM}$ of $\mathrm{K}^{+}$(Supplementary Fig. 8a). A trend towards an increased number of bursts at $20 \mathrm{pM}$ of AT-II was not significant (Supplementary Fig. 8a). Burst duration was not significantly altered (Supplementary Fig. 8b), and within bursts, the spiking frequency did not significantly differ between $C l_{c n} 2^{\mathrm{R} 180 \mathrm{Q} /+}$ mice and controls (Supplementary Fig. 8c). These results suggest that the augmented ClC-2 activity in $C l c n 2^{\mathrm{R} 180 \mathrm{Q} /+}$ mice mainly increases the likelihood of initiating bursting activity in the presence of AT-II, likely through depolarization compared to wildtype controls.

Clcn2 ${ }^{-/-}$mice show increased renin levels. To study whether ClC-2 plays a role in physiological aldosterone production beyond FH-II, we investigated $\mathrm{Clcn} 2^{-/-}$mice $^{29}$. Knockout mice had unaltered plasma aldosterone levels and Cyp11b2 expression (Fig. 4a, c). However, this occurred at the expense of elevated PRC and renal Ren1 expression (Fig. 4f, h), suggesting that activation of the renin-angiotensin system is required to maintain normal aldosterone levels in $\mathrm{Clcn} 2^{-/-}$mice, and that $\mathrm{ClC}-2$ is involved in normal zona glomerulosa function.

\section{Discussion}

The $C l c n 2^{\mathrm{R} 180 \mathrm{Q} /+}$ mouse model characterized here represents a genetic mouse model of FH-II with a rather mild phenotype. Previously characterized genetic mouse models with elevated aldosterone levels include a line derived from a mutagenesis screen with mutations in several candidate genes ${ }^{38}$, TASK channel knockout mice that so far lack a human Mendelian disease counterpart ${ }^{35,39-42}$, cryptochrome-null mice ${ }^{43}$ with pathophysiology that largely differs from that in known forms of human Mendelian aldosteronism and a recently published transgenic mouse model that expresses human CYP11B2 under the control of a human CYP11B1 promoter similar to the situation in $\mathrm{FH}_{-} \mathrm{I}^{44}$. A mouse model of FH-III did not consistently replicate the human phenotype (adrenal hyperplasia and elevated aldosterone levels) ${ }^{45}$.

The model described herein reproduces features of FH-II in humans, albeit with a less severe phenotype than in human index cases: elevated aldosterone levels associated with a mild increase 

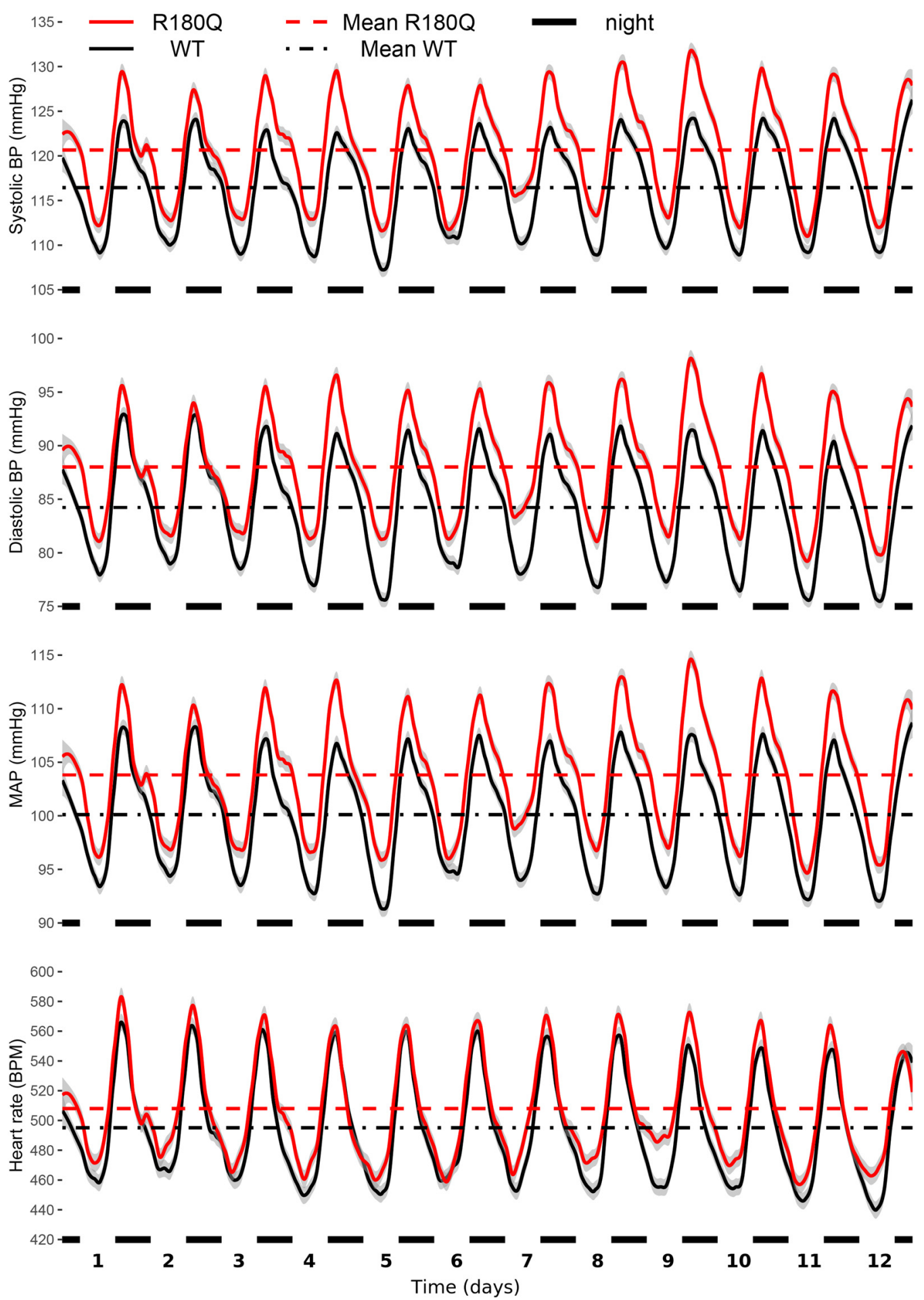

Fig. $7 \mathrm{Clcn} 2^{\mathrm{R} 180 \mathrm{Q} /+}$ mice have higher blood pressure. Blood pressure (BP) and heart rate (HR) of animals assessed through telemetry sensors. Shown are loess regressions of BP/HR of WT (black, $N=18$ biologically independent animals) and $\mathrm{Clcn} 2^{\mathrm{R} 180 \mathrm{Q} /+}$ (red, $N=18$ biologically independent animals) animals, with gray intervals denoting $95 \%$ confidence intervals for loess regressions. Horizontal axis shows time, with black markers noting nights (active periods of nocturnal animals). Horizontal lines show mean for the entire measurement period for WT (black dash-dotted) and Clcn2 $2^{\mathrm{R} 180 \mathrm{Q} /}+(\mathrm{red}$ dashed) animals. Nested-model likelihood ratio comparisons reveal significantly higher BP (systolic, $P=0.007$; diastolic $P=0.020, M A P, P=0.009$ ) of $\mathrm{Clcn} 2^{\mathrm{R} 180 \mathrm{Q} /+}$ animals than WT and unchanged HR $(p=0.225)$. Average (mean $\pm \mathrm{SEM}$ for all) systolic BP is $116.4 \pm 0.1 \mathrm{mmHg}(\mathrm{WT})$ and $120.6 \pm 0.1 \mathrm{mmHg}$ $\left(\mathrm{Clcn} 2^{\mathrm{R} 180 \mathrm{Q} /+}\right)$. Average diastolic BP is $84.2 \pm 0.1 \mathrm{mmHg}(\mathrm{WT})$ and $88.0 \pm 0.1 \mathrm{mmHg}\left(\mathrm{Clcn} 2^{\mathrm{R} 180 \mathrm{Q} /+}\right)$. Average MAP is $100.1 \pm 0.1 \mathrm{mmHg}(\mathrm{WT})$ and $103.8 \pm 0.1 \mathrm{mmHg}\left(\mathrm{Clcn} 2^{\mathrm{R} 180 \mathrm{Q} /+}\right)$. Average HR is $495.2 \pm 0.4 \mathrm{BPM}(\mathrm{WT})$ and $507.9 \pm 0.4 \mathrm{BPM}\left(\mathrm{Clcn} 2^{\mathrm{R} 180 \mathrm{Q} /+}\right)$ 


\section{a}
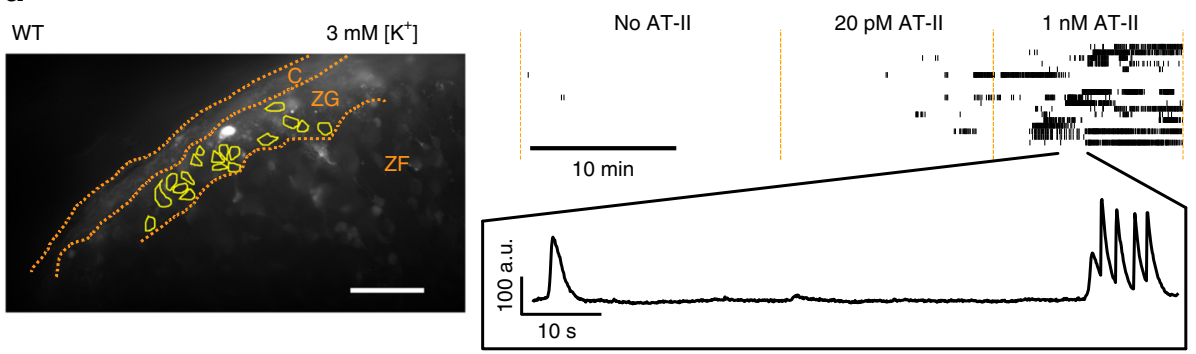

b

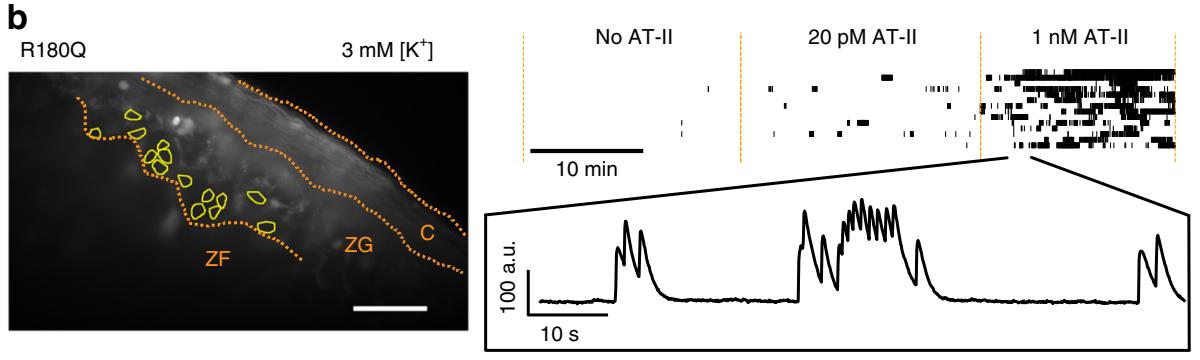

C
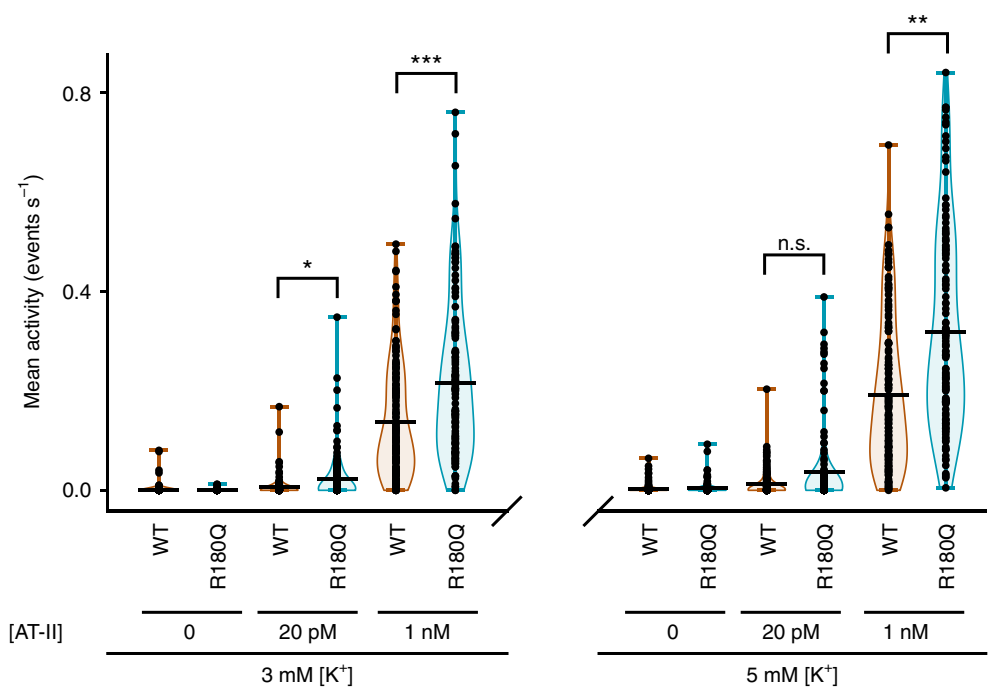

Fig. $8 \mathrm{Clcn} 2^{\mathrm{R} 180 \mathrm{Q} /+}$ mice have altered glomerulosa calcium signaling. a, b Left, representative average projection of 10 frames (1 s) without AT-II of a recording of calcium signals from acute adrenal slice preparations of either (a) wildtype (WT) or (b) Clcn2R180Q/+ mice (R180Q). Scale bar: $50 \mu$ m. Borders of the capsule (C), zona glomerulosa (ZG) and the outer part of the zona fasciculata (ZF) are shown in orange. Bright white spots likely correspond to apoptotic cells. Cells (yellow outlines) were selected from the recording, and mean intensity values over time were extracted. Top right, activity of all selected cells is shown in a burst plot. Cells are separated in rows along the $y$-axis, with time displayed along the $x$-axis. Detected spikes of the calcium signal are plotted as vertical lines with multiple spikes in close proximity merging into longer bars. Extracellular solution was perfused continuously and changed at the time points indicated. Representative examples of variations in the fluorescence recorded at $1 \mathrm{nM}$ of AT-II are shown in a magnified inset. (c) Violin plots of cellular activity (WT in orange, $\mathrm{Clcn} 2^{\mathrm{R} 180 \mathrm{Q} /+}$ in blue) in the zona glomerulosa as determined by the number of spikes per cell and second. All data points are shown, a black horizontal bar denotes the mean of the distribution. (N (cells): $3 \mathrm{mM}\left[\mathrm{K}^{+}\right]$, no AT-II $-\mathrm{WT}: \mathrm{N}=126, \mathrm{Clcn} 2^{\mathrm{R} 180 \mathrm{Q} /+} \mathrm{N}=$ 134, not tested; $3 \mathrm{mM}\left[\mathrm{K}^{+}\right], 20 \mathrm{pM}$ AT-II $-\mathrm{WT}: N=134, C l \mathrm{cn} 2^{\mathrm{R} 180 \mathrm{Q} /+} \mathrm{N}=134, \chi^{2}(1)=5.3413, P=0.0208\left(^{*}\right) ; 3 \mathrm{mM}\left[\mathrm{K}^{+}\right], 1 \mathrm{nM}$ AT-II $-N=157$,

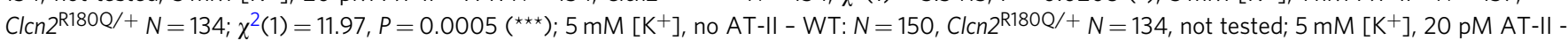
WT: $N=153, C l c n 2^{\mathrm{R} 180 \mathrm{Q} /}+N=134, \chi^{2}(1)=3.2957, P=0.0695$ (n.s.); $5 \mathrm{mM}\left[\mathrm{K}^{+}\right], 1 \mathrm{nM} \mathrm{AT}-\mathrm{II}-\mathrm{N}=154, \mathrm{Clcn} 2^{\mathrm{R} 180 \mathrm{Q} /}+N=134, \chi^{2}(1)=8.3487, P=$ $\left.0.0039{ }^{(\star \star}\right)$; likelihood ratio test)

in blood pressure and incomplete suppression of aldosterone synthase expression upon high-salt challenge ( $1.71 \%$ sodium diet, corresponding to the very high end of the spectrum of human salt consumption ${ }^{46,47}$ ). A trend towards elevated aldosterone levels in $\mathrm{Clcn} 2^{\mathrm{R} 180 \mathrm{Q} /+}$ mice after HSD was not significant, possibly due to small sample sizes. Unlike in most humans with FH-II, PRC was not suppressed in $C l c n 2^{\mathrm{R} 180 \mathrm{Q} /+}$ mice, likely due to only slightly elevated blood pressure. In line with this interpretation, male
Clcn $2^{\mathrm{R} 180 \mathrm{Q} /+}$ mice (with more severe phenotype) showed significantly lower Ren1 expression levels than WT mice. Similar observations (mildly elevated aldosterone, normal plasma renin concentration (PRC)) have been made in mice with tissue-specific deletion of TASK channels ${ }^{42}$. In such a setting, extended periods of high-salt treatment might be necessary to produce end-organ damage ${ }^{48,49}$. Unlike aldosterone synthase-transgenic mice with more pronounced hyperaldosteronism ${ }^{44}, C l c n 2^{\mathrm{R} 180 \mathrm{Q} /+}$ mice did 
not show upregulation of renal aldosterone target gene expression by real-time PCR. Interestingly, ARR was only elevated in male, but not in female mice. We excluded differences in Clcn2 expression as cause of this observed sex dimorphism. Changes during the mouse estrus cycle may cause increased variability in parameters of the renin-angiotensin-aldosterone system in female rodents ${ }^{50}$; in humans, aldosterone levels rise during the luteal phase ${ }^{51}$. In addition, sex dimorphism in adrenocortical tissue renewal was recently described, with female mice showing a 3 -fold higher turnover than males ${ }^{52}$, and sex dimorphism has previously been reported in a mouse model of $\mathrm{PA}^{41}$.

The rather mild phenotype observed in mice is consistent with incomplete penetrance in humans ${ }^{22}$ : In FH-II families, index cases typically had severe hyperaldosteronism and hypertension, which may be due to selection bias. However, in a large Australian kindred, three of eight mutation carriers did not have hypertension. Among these three subjects, ARRs were normal in one individual, borderline in a second and elevated in the third. These considerations suggest that factors other than the CLCN2 mutation contribute to disease expression. The mild phenotype of Clcn $2^{\mathrm{R} 180 \mathrm{Q} /+}$ mice could allow for the identification of such elusive genetic, epigenetic and/or environmental modifiers: Investigation of congenic mouse strains as well as effects of the microbiome or food on aldosterone levels and blood pressure would be instrumental ${ }^{53}$. A weakness of the current model is the absence of cardiac or renal damage. Homozygous mice $\left(C l c n 2^{\mathrm{R} 180 \mathrm{Q} / \mathrm{R} 180 \mathrm{Q}}\right)$ may show a more severe phenotype and could enable studies of target organ damage.

The absence of macroscopic or microscopic adrenal hyperplasia in $C l c n 2^{\mathrm{R} 180 \mathrm{Q} /+}$ mice suggests that CLCN2 mutations in humans and in mice may have a predominant effect on aldosterone synthesis rather than cellular proliferation; microscopic images of FH-II patients were unavailable ${ }^{22}$. A CLCN2 mutation has only very recently been described in an aldosteroneproducing adenoma; however, this was small tumor ${ }^{25}$, similar to those with CACNA1D and ATPase mutations.

The $C l c n 2^{\mathrm{R} 180 \mathrm{Q} /+}$ mouse model also allowed us to further investigate the impact of the mutation on the cellular level. Calcium imaging in acute slice preparations revealed only very low activity of the zona glomerulosa in unstimulated adrenal glands from either WT or Clcn $2^{\mathrm{R} 180 \mathrm{Q} /+}$ mice, similar to results in WT mice by Penton and colleagues ${ }^{35}$. Stimulation with AT-II led to an increase in calcium signaling and the appearance of calcium bursts, further defining the mechanism by which aldosterone synthesis is regulated under physiological conditions; Penton and colleagues even observed continuous activity without intermittent silent periods upon stimulation with extremely high AT-II and $\mathrm{K}^{+}$concentrations. $C l c n 2^{\mathrm{R} 180 \mathrm{Q} /+}$ mice showed an increase of the mean activity per cell compared to controls in the presence of AT-II, demonstrating a higher sensitivity for stimulation, accounting for the increased aldosterone production in mice and patients. A significant increase in the number of bursts could only be observed at $1 \mathrm{nM}$ of AT-II while the trend was also visible at 20 pM but not significant, likely due to the smaller overall number of bursts and small effect size. In contrast, frequencies during bursting and burst lengths remained unchanged. These results support a main role of $\mathrm{ClC}-2$ in cellular depolarization ${ }^{22}$ and initiation of calcium signals in the form of bursts.

Future studies may compare the phenotype, adrenal morphology and calcium signaling of the $C l c n 2^{\mathrm{R} 180 \mathrm{Q} /+}$ model with other models of familial hyperaldosteronism. Mouse models with gain-of-function mutations in calcium channels have so far not been described, but would be particularly interesting to assess. The physiological role of ClC-2 in zona glomerulosa function, suggested by elevated renin expression in Clcn2 knockout mice, also warrants further investigation.

\section{Methods}

Generation of the mouse model. The mouse model C57BL/6N-Clcn $2^{\mathrm{em} 1 \mathrm{Uis}}$ $\left(\mathrm{Cl} n 2^{\mathrm{R} 180 \mathrm{Q} /+}\right)$ was generated by Cyagen Biosciences, Inc., using the CRISPR/Cas 9 technology. The guide RNA (gRNA) was 5'-CAGCACCACTCCCCGAAGG ATGG-3' (protospacer adjacent motif (PAM) sequence underscored). A donor oligonucleotide was used to mutate CGG encoding Arg180 (NM_009900.2) to CAG (encoding Gln) by homology-directed repair (5'-ATGCTCCTGGGAACAT GTATCTCTGCAGGGTCTGGCATCCCCGAAATGAAAACCATCCTTCAGGG AGTGGTGCTGAAAGAATACCTCACCCTCAAGACCTTTGTAGCTA $\overline{A G G T C}$ ATTGGGCTA-3'; mutated codon underscored). gRNA and Cas9 mRNA were generated by in vitro transcription and co-injected with the donor oligonucleotide into 460 fertilized eggs, followed by embryo transfer. Thirteen of 15 surrogates became pregnant. The offspring was genotyped by PCR (Clcn2-F: 5'-GTCTTATC ATTGTGTCCCAGTGGCAG-3'; Clcn2-R: 5' - ATCTCCGTGTTCCGGGACTCA TG- $3^{\prime}$ ) and Sanger sequencing ( $5^{\prime}$-GGGGCTTAAACACCAACATCTTACTC- $3^{\prime}$ ). Three of 60 pups carried a heterozygous p.Arg180Gln variant without additional frameshift variants. In the two mice used for further breeding, mutations in the five top off-target sites were excluded by Sanger sequencing (Supplementary Table 1). To genotype further generations, primers Mouse Clcn2-F: 5'-GTGTCCCAGTGGC AGGCAAGG-3' and Mouse Clcn2-R: 5'-CAGTGTCAGCTTGGGCTCAGCAG-3' were used. Animals were backcrossed to $\mathrm{C} 57 \mathrm{BL} / 6 \mathrm{~N}$ three times before experiments were conducted.

Clcn $2^{\mathrm{R} 180 \mathrm{Q} /+}$ mice can be obtained exclusively for non-commercial research purposes (material transfer agreement). Recipients must treat, keep and use mice according to applicable regulations (e.g., animal welfare and protocols) and pay for packing, shipping, and handling. Recipients must not distribute the mice, their progeny or other materials derived from these mice without written consent of the provider and must cite this publication.

Animals and sample collection. The $C l c n 2^{-/-}$strain was kindly provided by Dr Thomas Jentsch, the generation of this mouse model was described by Bösl et al. ${ }^{29}$. All strains were bred and housed at the Zentrale Einrichtung für Tierforschung und wissenschaftliche Tierschutzaufgaben (Heinrich Heine University Düsseldorf), the Forschungseinrichtungen für Experimentelle Medizin (Charité-Uni-

versitätsmedizin Berlin) and/or the Forschungszentrum Jülich (only Clcn2 $2^{\mathrm{R} 180 \mathrm{Q} /+}$ mice studied at age 11 months). They were maintained under specific pathogenfree conditions in a 12-h light/dark cycle with ad libitum access to food and water All animal experiments were approved by the local authorities (Landesamt für Natur, Umwelt und Verbraucherschutz Nordrhein-Westfalen and Landesamt für Gesundheit und Soziales Berlin) and performed under consideration of all relevant ethical regulations.

To harvest organs for RNA extraction, mice were anesthetized using ketamine $100 \mathrm{mg} \mathrm{kg}^{-1}+$ xylazine $10 \mathrm{mg} \mathrm{kg}^{-1}$ i.p., followed by cervical dislocation. After opening of the thoracic cavity, blood was collected by cardiac puncture and transferred into Vacutainer EDTA tubes (Becton Dickinson). Blood samples were centrifuged $\left(10 \mathrm{~min}, 2000 \mathrm{~g}, 4^{\circ} \mathrm{C}\right)$, and the supernatant (plasma) was stored at $-20{ }^{\circ} \mathrm{C}$ until further analysis. Adrenal glands were harvested and weighed, and kidneys and brains were collected. All organs were stored in tubes containing RNAlater RNA stabilization reagent (Qiagen; $4{ }^{\circ} \mathrm{C}$ overnight, then $-20^{\circ} \mathrm{C}$ ) until RNA extraction. For histology, animals were anaesthetized using ketamine $100 \mathrm{mg}$ $\mathrm{kg}^{-1}+$ xylazine $10 \mathrm{mg} \mathrm{kg}^{-1}$ i.p., and organs were fixed by cardiac perfusion. A $23 \mathrm{G}$ blood collection set (Becton Dickinson) was inserted into the left ventricular chamber. After opening of the right atrium, the heart was perfused with $10 \mathrm{~mL}$ PBS containing $10 \mathrm{U} / \mathrm{mL}$ heparin, followed by $10 \mathrm{~mL} 4 \%$ paraformaldehyde in $\mathrm{PBS}$ (pH 7.4; Santa Cruz). Adrenal glands were harvested and weighed. In addition, kidneys, brains, hearts, and testis were removed. All organs were fixed in $10 \%$ formalin solution (neutral buffered; Sigma Aldrich) for 18-24h. 11-month-old mice were anesthetized with isoflurane ( $1 \mathrm{ml} / \mathrm{l}$ open drop). Following cervical dislocation, hearts, kidneys, and adrenal glands were harvested and kept in PBS $+0.03 \% \mathrm{NaN}_{3}$ for $72 \mathrm{~h}$ after fixation until further processing. Samples were dehydrated in ethanol $(70 \%, 80 \%, 96 \%$, and $100 \%)$ and xylene, followed by embedding into paraffin (Merck Millipore) and storage at $4{ }^{\circ} \mathrm{C}$ (for in situ hybridization) or room temperature until further investigations. Spot urine was collected over three days in the morning followed by 1 week of recovery and blood collection via cardiac puncture (26G needle, $1 \mathrm{ml}$ syringe) into Microtainer (Lithium-Heparin) tubes (Becton Dickinson). One group of mice per genotype received a HSD (E15431-34 containing $1.71 \%$ sodium, Ssniff Spezialdiäten) and $1 \% \mathrm{NaCl}$ via drinking water for 4 weeks. Mice were euthanized by cervical dislocation under anesthesia, and blood and organs were collected as above.

Quantitative real-time PCR. Total RNA from adrenal glands and kidneys was isolated using the miRNeasy Mini Kit (Qiagen). Concentration and purity was assessed with a Nanodrop 2000 (Thermo Scientific). After reverse transcription of RNA using Quantitect RT Kit (Qiagen), Taqman gene expression assays (Applied Biosystems) for Gapdh (Mm99999915_g1, housekeeping gene), Cyp11b2

(Mm00515624_m1) and Clcn2 (Mm01344259_m1) were performed for adrenal samples. Gapdh (primers 5'-TGTAGACCATGTAGTTGAGGTCA-3' and 5'-AGG TCGGTGTGAACGGATTTG-3'), Ren 1 (5'-TCTGGGCACTCTTGTTGCTC-3' and $5^{\prime}$-GGGGGAGGTAAGATTGGTCAA-3'), Slc13a2 (5'-CGAGAGTAATCCA GCAGTA- $3^{\prime}$ and $5^{\prime}$-ATGAAGAGATTAACAAGAACAGAA- $\left.3^{\prime}\right)^{54}$ and $S g k 1$ 
(5'-ATGCAGTAAACCAGCCGGT-3' and 5'-TGATCCATCTTCGTACCCGT-3') were amplified from kidney cDNA using Power SYBR Green PCR Master Mix (Applied Biosystems). Gene expression was evaluated relative to Gapdh, and mean $\Delta \mathrm{CT}$ of WT controls and expressed as $2^{\Delta \Delta \mathrm{Ct}}$ (fold change).

H\&E and Sirius red staining. Formalin-fixed, paraffin-embedded (FFPE) adrenal glands, kidneys, brains, hearts and testes of 12 to 16 weeks old (WT, Clcn $2^{\mathrm{R} 180 \mathrm{Q} /+}$ ), 9 weeks old $\left(\mathrm{Clcn}^{-/-29}\right)$ and 11 -month-old mice (WT, Clcn $2^{\mathrm{R} 180 \mathrm{Q} /+}$ ) were cut into $5 \mu \mathrm{m}$ sections. After deparaffinization by xylene and rehydration in ethanol $(100 \%, 95 \%, 90 \%, 80 \%$, and $70 \%)$ and deionized water, the sections were incubated in hematoxylin (Sigma Aldrich) for $3 \mathrm{~min}$. Sections were rinsed in tap water, dipped $8-12 \mathrm{x}$ in acid ethanol $(0.25 \% \mathrm{HCl}$ in $70 \%$ ethanol), incubated in eosin (Carl Roth) for $30 \mathrm{~s}$, dehydrated in $100 \%$ ethanol and mounted using VectaMount (Vector Labs).

For Sirius red staining, sections of 11-month-old mice were deparaffinized and rehydrated as above, incubated in hematoxylin for $8 \mathrm{~min}$ and washed in tap water for $5 \mathrm{~min}$. Sections were incubated in $0.25 \mathrm{~g} / \mathrm{L}$ Direct Red 80 (Sigma Aldrich) in $1.3 \%$ picric acid (Sigma Aldrich) for $60 \mathrm{~min}$, washed in $0.5 \%$ acetic acid for $1 \mathrm{~min}$, dehydrated (70\%, 95\% and $100 \%$ ethanol and xylene) and mounted using VectaMount.

In situ hybridization. Cyp11b2 in situ hybridization in FFPE adrenal glands was performed using the RNAscope 2.5 HD Assay - Brown (Advanced Cell Diagnostics). $5 \mu \mathrm{m}$ sections were treated according to the manufacturer's instructions (document numbers: 322452 and 322310-USM). Probes were Mm-Cyp11b2 (Cat No. 505851), and DapB (Cat No. 310043, negative control).

Immunohistochemistry. $5 \mu \mathrm{m}$ kidney or heart sections of 11-month-old mice $\left(\mathrm{WT}, \mathrm{Clcn} 2^{\mathrm{R} 180 \mathrm{Q} /+}\right.$ ) were heated at $60^{\circ} \mathrm{C}$ for $1 \mathrm{~h}$, deparaffinized using xylene and rehydrated in ethanol $(100 \%, 95 \%, 90 \%, 80 \%$, and $70 \%)$ and deionized water. After antigen retrieval by boiling two times in $10 \mathrm{mM}$ sodium citrate $+0.05 \%$ Tween 20 in $\mathrm{H}_{2} \mathrm{O}$ (pH 6.0) and $15 \mathrm{~min}$ incubation after each boiling, sections were permeabilized in $0.2 \%$ Triton X-100 in PBS ( 15 min), incubated in $3 \% \mathrm{H}_{2} \mathrm{O}_{2}$ in PBS to remove peroxidase $(10 \mathrm{~min}$ ) and blocked using $10 \%$ BSA (Sigma Aldrich, St. Louis, MO, USA) in PBS for $1 \mathrm{~h}$, followed by incubation with primary antibody against F4/80 (1:100; sc-377009 HRP; Santa Cruz) overnight at $4{ }^{\circ} \mathrm{C}(10 \%$ BSA in PBS was used for corresponding controls). After DAB staining (Becton Dickinson) for $30 \mathrm{~s}$ and counterstaining using hematoxylin (Sigma Aldrich) for $10 \mathrm{~min}$, slides were mounted with VectaMount.

Aldosterone ELISA. Plasma aldosterone levels were measured by enzyme-linked immunosorbent assay (ELISA, RE52301; IBL International GmbH) according to the manufacturer's instructions.

Determination of PRC. PRC was determined by measuring the capability of the sample to generate Angiotensin I (AT-I) from excess renin substrate ${ }^{55}$. AT-I concentrations were determined using a radioimmunoassay (RIA) with the following modifications: high binding RIA tubes (Greiner Bio-One) were coated with $300 \mu \mathrm{l}$ of 1:60,000 diluted anti-AT-I antibodies for $20 \mathrm{~h}$ at $4{ }^{\circ} \mathrm{C}$. After washing with TRIS buffer, tubes were incubated with $400 \mu \mathrm{l}$ blocking buffer containing $0.5 \%$ BSA for $2 \mathrm{~h}$ at room temperature to prevent unspecific binding. Tubes were washed again and stored at $-20^{\circ} \mathrm{C}$. For the RIA, $3 \times 50 \mu \mathrm{l}$ of the pre-treated samples and $200 \mu \mathrm{l}^{125}$ I-labeled AT-I with an activity of $5000 \mathrm{cpm}$ (Amersham Biosciences) were added to the coated tubes und incubated for $20 \mathrm{~h}$ at room temperature. After three times washing with $1 \mathrm{ml}$ washing buffer, the AT-I concentration was measured using a $\gamma$-counter (Berthold LD 2111). The concentration was determined according to the standard curve.

Determination of electrolytes. Plasma and urine electrolytes $\left(\mathrm{K}^{+}, \mathrm{Na}^{+}, \mathrm{Cl}^{-}\right)$were measured at the Animal Phenotyping Facility at Max-Delbrück-Centrum (MDC) Berlin using an AU480 Clinical Chemistry Analyzer (Beckman Coulter).

Blood pressure measurements. Blood pressure was measured via telemetry. A telemetric catheter (DSI PhysioTel PA-C10; weight 1.4 g; Data Science International) was implanted in 3-month-old male mice under general anesthesia using ketamine $100 \mathrm{mg} \mathrm{kg}^{-1}+$ xylazine $10 \mathrm{mg} \mathrm{kg}^{-1}$ i.p. Via a median neck incision, the right common carotid artery was located and dissected. The carotid artery was ligated near the bifurcation, and two loops were placed caudal to the ligature. Caudally the blood flow of the common carotid artery was stopped using a miniature clamp, an angled cannula tip was inserted, and the catheter was placed into the vessel. After releasing the mini clamp, the catheter was pushed forward by $1.5 \mathrm{~cm}$ towards the aortic bifurcation and fixed by closing the loops. A subcutaneous cavity was prepared for the transmitter. The wound was closed using 3-0 Prolene. Rimadyl $5 \mathrm{mg} / \mathrm{kg}$ s.c. was given intraoperatively and on the first, second, and third postoperative day. Mice were fed a standard diet (V1124-300 containing $0.24 \%$ sodium, ssniff Spezialdiäten). After 1 week of recovery, blood pressure and heart rate were recorded for twelve days (every 5 min, each $10 \mathrm{~s}$ ). Locomotor activity was recorded based on signal strength changes that occurred with changes in the orientation of the animal relative to the receiver or changes in the distance of the animal from the receiver. Quality controlled sensor data were analyzed by mixed effect modeling using the $\operatorname{lm} 4^{56} \mathrm{R}$ package, with animal and time of day as random effects, day-night status and genotype as fixed effects. Significance of genotype, was done through likelihood ratio test comparison with a model omitting the tested predictor as implemented in the $\operatorname{lm} t e s{ }^{57} \mathrm{R}$ package. Nights were defined as periods when light was off (6 p.m. to 6 a.m. or 7 p.m. to 7 a.m.). Blood pressure data were plotted as loess regressions using the ggplot $2^{58} \mathrm{R}$ package, separately by genotype, showing $95 \%$ confidence interval of loess parameters in the figure.

Calcium imaging of acute adrenal slices. To prepare the adrenal slices, mice were anesthetized with isoflurane $\left(1 \mathrm{ml} \mathrm{l}^{-1}\right.$ open drop), followed by cervical dislocation. Both adrenal glands were rapidly removed and transferred to ice-cold bicarbonatebuffered saline (BBS: $125 \mathrm{mM} \mathrm{NaCl}, 2 \mathrm{mM} \mathrm{KCl}, 26 \mathrm{mM} \mathrm{NaHCO}_{3}, 0.1 \mathrm{mM} \mathrm{CaCl}_{2}$, $5 \mathrm{mM} \mathrm{MgCl}, 10 \mathrm{mM}$ glucose, continuously gassed with $5 \% \mathrm{CO}_{2} / 95 \% \mathrm{O}_{2}$ ). Surrounding fat was removed and adrenal glands embedded in $4 \%$ low-melting temperature agarose in BBS. Agarose blocks were mounted on a vibratome (7000 smz-2, Campden Instruments) and cut into $100-150 \mu \mathrm{m}$ slices at $4^{\circ} \mathrm{C}$. Slices were kept at $35^{\circ} \mathrm{C}$ for $30 \mathrm{~min}$ in BBS, followed by storage for up to $6 \mathrm{~h}$ in BBS supplemented with $2 \mathrm{mM} \mathrm{CaCl}_{2}$ at room temperature. Adrenal slices were placed in a cell culture insert (Merck Millipore) in one well of a 24 well plate for staining. The outer reservoir was filled with $800 \mu \mathrm{l}$ of BBS (supplemented with $2 \mathrm{mM} \mathrm{Ca}^{2+}$ ) Calbryte 520 AM (AAT Bioquest) dissolved in DMSO + 2\% Pluronic F-127 was diluted to a concentration of $9.2 \mu \mathrm{M}$ in $200 \mu \mathrm{l}$ BBS (supplemented with $2 \mathrm{mM}$ $\mathrm{Ca}^{2+}$ ) and filled into the inner reservoir on top of the adrenal slice. Loading occurred on top of a heating block set to $37^{\circ} \mathrm{C}$ for $1-1.5 \mathrm{~h}$ while continuously gassing the outer reservoir with $5 \% \mathrm{CO}_{2} / 95 \% \mathrm{O}_{2}$. After dye loading, slices were transferred to the recording chamber. The chamber was continuously perfused with recirculating solution from a reservoir gassed with $5 \% \mathrm{CO}_{2} / 95 \% \mathrm{O}_{2}$ and heated in line via a heating coil, resulting in a temperature of the perfusion solution of $33 \pm 1^{\circ} \mathrm{C}$. During camera exposure, fluorescence was excited using a blue LED (pE-300 ultra, CoolLED), passing through a $474 / 27 \mathrm{~nm}$ bandpass filter (AHF Analysentechnik) and recorded using a $40 \times / 0.8 \mathrm{NA}$ objective (Olympus), a 432/ 523/702 triple-band filter (AHF Analysentechnik) and an OptiMOS camera (Qimaging). Images were taken every $100 \mathrm{~ms}$ with an exposure setting of 10-15 ms. Regions of interest corresponding to individual cells were chosen manually from recorded images using Fiji ${ }^{59,60}$. Criteria for selection were: (1) appearance in glomerular structures located near the capsule and (2) visible activity during the perfusion with $1 \mathrm{nM}$ angiotensin II (AT-II). In total, slices were prepared and

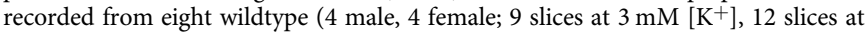
$5 \mathrm{mM}\left[\mathrm{K}^{+}\right]$) and eight $C l c n 2^{\mathrm{R} 180 \mathrm{Q} /+}$ mice (4 male, 4 female; 11 slices at $3 \mathrm{mM} \mathrm{[ \textrm {K } ^ { + } ]}$ and 10 slices at $5 \mathrm{mM}\left[\mathrm{K}^{+}\right]$).

Calcium signals were extracted and analyzed using a custom Python script (Supplementary Software 1). Zona glomerulosa calcium signals in acute adrenal slices were identified based on sudden increases in intracellular calcium concentration, followed by a slow decay ${ }^{35}$. For calcium spike detection, background noise and the signal decay caused by dye bleaching were removed by subtracting the minimum within a rolling window of 50 frames (5 s). Afterwards, the change in signal from one time point to the next was calculated to identify spikes generated by sudden rises of the intracellular calcium concentration. This method allowed for successful identification of isolated spikes as well as spikes within bursts, even if the baseline of the calcium concentration did not reach basal levels. To separate true activity from random background fluctuations, a manually set threshold for spike registration (above the background level as determined in parts of the recording without activity) was applied. Remaining artifacts from motion of the slice itself and perfusion were removed after manual inspection of all detected spikes. The code and a sample dataset can be found in Supplementary Code 1. Calcium spikes in zona glomerulosa cells appeared to become more temporally clustered with increasing AT-II (Fig. 8a, b). To define these clusters of activity (bursts) and separate them from isolated spikes and one another, we first determined the intervals between successive calcium spikes. These interspike intervals are shorter during bursts (one spike quickly follows the next) while they get longer outside of bursts. Plotting the distribution of the interspike intervals reveals a relatively large peak towards shorter values (few seconds) corresponding to the typical distances between spikes during bursting (Supplementary Fig. 9). Increasing $\left[\mathrm{K}^{+}\right]$and AT-II leads to more bursting (Fig. 8) resulting in more recorded interspike intervals during bursts and thus a more defined distribution at shorter values (Supplementary Fig. 9). These distributions were similar in $C l c n 2^{\mathrm{R} 180 \mathrm{Q} /+}$ and controls (Supplementary Fig. 9a, b), with a trend towards more bursting at increasing $\left[\mathrm{K}^{+}\right]$and AT-II levels represented by a more defined distribution of values below $5 \mathrm{~s}$ (Supplementary Fig. 9a, b). Based on these interspike interval distributions, we defined bursts as clusters of activity (with at least three spikes) containing less than $4 \mathrm{~s}$ of quiescence.

Single cell calcium signaling data were analyzed by mixed effect modeling using the lme $4^{56} \mathrm{R}$ package, with individual animals as random and genotypes as fixed effects with random intercepts. Inclusion of individual slices or sex into the model did not significantly improve the model as determined by likelihood ratio comparisons. Significance testing was performed through likelihood ratio test comparison with a model omitting the fixed effect using a double sided $\chi^{2}$ test. 
Statistics. Raw data were analyzed using Microsoft Office Excel 2016 and GraphPad Prism 7.00 or 8.2.0 as well as R for blood pressure analysis and calcium imaging (see above for details). Statistical tests were performed two-sided and are specified in the figure legends. To account for pseudoreplication, linear mixed modeling was used in the analysis of blood pressure and imaging data ${ }^{61}$.

Reporting summary. Further information on research design is available in the Nature Research Reporting Summary linked to this article.

\section{Data availability}

Datasets generated during the current study are included in the article and supplementary information files, or otherwise available from the corresponding author upon request.

\section{Code availability}

Custom code is available as Supplementary Software 1.

Received: 7 February 2019; Accepted: 17 October 2019;

Published online: 14 November 2019

\section{References}

1. Asher, C., Wald, H., Rossier, B. C. \& Garty, H. Aldosterone-induced increase in the abundance of $\mathrm{Na}+$ channel subunits. Am. J. Physiol. 271, C605-C611 (1996).

2. Wald, H., Garty, H., Palmer, L. G. \& Popovtzer, M. M. Differential regulation of ROMK expression in kidney cortex and medulla by aldosterone and potassium. Am. J. Physiol. 275, F239-F245 (1998).

3. Conn, J. W. Presidential address. I. Painting background. II. Prim. Aldosteronism New Clin. Syndr. J. Lab. Clin. Med. 45, 3-17 (1955).

4. Funder, J. W. et al. The management of primary aldosteronism: case detection, diagnosis, and treatment: an endocrine society clinical practice guideline. $J$. Clin. Endocrinol. Metab. 101, 1889-1916 (2016).

5. Monticone, S. et al. Prevalence and clinical manifestations of primary aldosteronism encountered in primary care practice. J. Am. Coll. Cardiol. 69, 1811-1820 (2017).

6. Rossi, G. P. et al. A prospective study of the prevalence of primary aldosteronism in 1,125 hypertensive patients. J. Am. Coll. Cardiol. 48, 2293-2300 (2006).

7. Milliez, P. et al. Evidence for an increased rate of cardiovascular events in patients with primary aldosteronism. J. Am. Coll. Cardiol. 45, 1243-1248 (2005).

8. Monticone, S. et al. Cardiovascular events and target organ damage in primary aldosteronism compared with essential hypertension: a systematic review and meta-analysis. Lancet Diabetes Endocrinol. 6, 41-50 (2018).

9. Choi, $\mathrm{M}$. et al. $\mathrm{K}+$ channel mutations in adrenal aldosterone-producing adenomas and hereditary hypertension. Science 331, 768-772 (2011).

10. Scholl, U. I. et al. Somatic and germline CACNA1D calcium channel mutations in aldosterone-producing adenomas and primary aldosteronism. Nat. Genet. 45, 1050-1054 (2013).

11. Azizan, E. A. et al. Somatic mutations in ATP1A1 and CACNA1D underlie a common subtype of adrenal hypertension. Nat. Genet. 45, 1055-1060 (2013).

12. Beuschlein, F. et al. Somatic mutations in ATP1A1 and ATP2B3 lead to aldosterone-producing adenomas and secondary hypertension. Nat. Genet. 45, 440-444 (2013).

13. Omata, K. et al. Cellular and genetic causes of idiopathic hyperaldosteronism. Hypertension 72, 874-880 (2018).

14. Scholl, U. I. Unanswered questions in the genetic basis of primary aldosteronism. Horm. Metab. Res. 49, 963-968 (2017).

15. Nishimoto, K. et al. Aldosterone-stimulating somatic gene mutations are common in normal adrenal glands. Proc. Natl Acad. Sci. U. S. A. 112, E4591-E4599 (2015)

16. Seidel, E. \& Scholl, U. I. Genetic mechanisms of human hypertension and their implications for blood pressure physiology. Physiol. Genomics 49, 630-652 (2017).

17. Sutherland, D. J., Ruse, J. L. \& Laidlaw, J. C. Hypertension, increased aldosterone secretion and low plasma renin activity relieved by dexamethasone. Can. Med. Assoc. J. 95, 1109-1119 (1966).

18. Lifton, R. P. et al. A chimaeric 11 beta-hydroxylase/aldosterone synthase gene causes glucocorticoid-remediable aldosteronism and human hypertension. Nature 355, 262-265 (1992).

19. Scholl, U. I. et al. Hypertension with or without adrenal hyperplasia due to different inherited mutations in the potassium channel KCNJ5. Proc. Natl Acad. Sci. U. S. A. 109, 2533-2538 (2012).
20. Scholl, U. I. et al. Recurrent gain of function mutation in calcium channel CACNA1H causes early-onset hypertension with primary aldosteronism. eLife 4, https://doi.org/10.7554/eLife.06315 (2015).

21. Daniil, G. et al. CACNA1H mutations are associated with different forms of primary aldosteronism. EBioMedicine 13, 225-236 (2016).

22. Scholl, U. I. et al. CLCN2 chloride channel mutations in familial hyperaldosteronism type II. Nat. Genet. 50, 349-354 (2018).

23. Fernandes-Rosa, F. L. et al. A gain-of-function mutation in the CLCN2 chloride channel gene causes primary aldosteronism. Nat. Genet. 50, 355-361 (2018).

24. Stowasser, M. et al. Familial hyperaldosteronism type II: five families with a new variety of primary aldosteronism. Clin. Exp. Pharmacol. Physiol. 19, 319-322 (1992).

25. Dutta, R. K. et al. Case report: a somatic mutation in CLCN2 identified in a sporadic aldosterone producing adenoma. Eur. J. Endocrinol., https://doi.org/ 10.1530/EJE-19-0377 (2019)

26. Tamura, A. et al. Somatic KCNJ5 mutation occurring early in adrenal development may cause a novel form of juvenile primary aldosteronism. $\mathrm{Mol}$ Cell. Endocrinol. https://doi.org/10.1016/j.mce.2016.07.031 (2016).

27. Spat, A. \& Hunyady, L. Control of aldosterone secretion: a model for convergence in cellular signaling pathways. Physiol. Rev. 84, 489-539 (2004)

28. Chorvatova, A., Gendron, L., Bilodeau, L., Gallo-Payet, N. \& Payet, M. D. A Ras-dependent chloride current activated by adrenocorticotropin in rat adrenal zona glomerulosa cells. Endocrinology 141, 684-692 (2000).

29. Bosl, M. R. et al. Male germ cells and photoreceptors, both dependent on close cell-cell interactions, degenerate upon $\mathrm{ClC}-2 \mathrm{Cl}(-)$ channel disruption. $E M B O$ J. 20, 1289-1299 (2001).

30. Blanz, J. et al. Leukoencephalopathy upon disruption of the chloride channel ClC-2. J. Neurosci. 27, 6581-6589 (2007).

31. Hansen, P. B. et al. Plasma renin in mice with one or two renin genes. Acta Physiol. Scand. 181, 431-437 (2004)

32. Kim, G. H. et al. The thiazide-sensitive $\mathrm{Na}-\mathrm{Cl}$ cotransporter is an aldosteroneinduced protein. Proc. Natl Acad. Sci. U. S. A. 95, 14552-14557 (1998).

33. Naray-Fejes-Toth, A., Canessa, C., Cleaveland, E. S., Aldrich, G. \& Fejes-Toth G. sgk is an aldosterone-induced kinase in the renal collecting duct. Eff. Epithel. Na+ Channels J. Biol. Chem. 274, 16973-16978 (1999).

34. Funder, J. W. Primary aldosteronism and salt. Pflug. Arch. 467, 587-594 (2015).

35. Penton, D. et al. Task3 potassium channel gene invalidation causes low renin and salt-sensitive arterial hypertension. Endocrinology 153, 4740-4748 (2012)

36. Schulz, A., Jankowski, J., Zidek, W. \& Jankowski, V. Absolute quantification of endogenous angiotensin II levels in human plasma using ESI-LC-MS/MS. Clin. Proteom. 11, 37 (2014).

37. Gomolak, J. R. \& Didion, S. P. Angiotensin II-induced endothelial dysfunction is temporally linked with increases in interleukin-6 and vascular macrophage accumulation. Front Physiol. 5, 396 (2014).

38. Perez-Rivas, L. G. et al. Genetic characterization of a mouse line with primary aldosteronism. J. Mol. Endocrinol. 58, 67-78 (2017).

39. Davies, L. A. et al. TASK channel deletion in mice causes primary hyperaldosteronism. Proc. Natl Acad. Sci. U. S. A. 105, 2203-2208 (2008).

40. Guagliardo, N. A. et al. TASK-3 channel deletion in mice recapitulates lowrenin essential hypertension. Hypertension 59, 999-1005 (2012).

41. Heitzmann, D. et al. Invalidation of TASK1 potassium channels disrupts adrenal gland zonation and mineralocorticoid homeostasis. EMBO J. 27, 179-187 (2008).

42. Guagliardo, N. A. et al. Adrenal tissue-specific deletion of TASK channels causes aldosterone-driven angiotensin ii-independent hypertension. Hypertension 73, 407-414 (2019).

43. Nugrahaningsih, D. A. et al. Chronic hyperaldosteronism in cryptochromenull mice induces high-salt- and blood pressure-independent kidney damage in mice. Hypertens. Res. 37, 202-209 (2014).

44. Gu, H. et al. Salt-dependent blood pressure in human aldosterone synthasetransgenic mice. Sci. Rep. 7, 492 (2017)

45. Lichtenauer, U. et al. Establishment of an in vivo model for KCNJ5 dependent hyperaldosteronism. Exp. Clin. Endocrinol. Diabetes 123, P09_25 (2015).

46. Faraco, G. et al. Dietary salt promotes neurovascular and cognitive dysfunction through a gut-initiated TH17 response. Nat. Neurosci. 21, 240-249 (2018).

47. Weidemann, B. J. et al. Dietary sodium suppresses digestive efficiency via the renin-angiotensin system. Sci. Rep. 5, 11123 (2015).

48. Brilla, C. G. \& Weber, K. T. Mineralocorticoid excess, dietary sodium, and myocardial fibrosis. J. Lab. Clin. Med. 120, 893-901 (1992).

49. Pimenta, E. et al. Cardiac dimensions are largely determined by dietary salt in patients with primary aldosteronism: results of a case-control study. J. Clin. Endocrinol. Metab. 96, 2813-2820 (2011).

50. Ganong, W. F. Reproduction and the renin-angiotensin system. Neurosci. Biobehav. Rev. 19, 241-250 (1995).

51. Szmuilowicz, E. D. et al. Relationship between aldosterone and progesterone in the human menstrual cycle. J. Clin. Endocrinol. Metab. 91, 3981-3987 (2006). 
52. Grabek, A. et al. The adult adrenal cortex undergoes rapid tissue renewal in a sexspecific manner. Cell Stem Cell, https://doi.org/10.1016/j.stem.2019.04.012 (2019).

53. Wilck, N. et al. Salt-responsive gut commensal modulates TH17 axis and disease. Nature 551, 585-589 (2017).

54. Davies, M. R. et al. The thiazide-sensitive co-transporter promotes the development of sodium retention in mice with diet-induced obesity. Kidney Blood Press. Res. 40, 509-519 (2015).

55. Peters, J. et al. Increased adrenal renin in transgenic hypertensive rats, TGR (mREN2)27, and its regulation by cAMP, angiotensin II, and calcium. J. Clin. Invest. 91, 742-747 (1993).

56. Bates, D. M., Bolker, M., Walker, B. \& Fitting, S. Linear mixed-effects models using lme4. J. Stat. Softw. 67, 1-48 (2015).

57. Zeileis, A. \& Hothorn, T. Diagnostic checking in regression relationships. $R$. News 2, 7-10 (2002).

58. Wickham, H. ggplot2: Elegant Graphics for Data Analysis (Springer-Verlag, 2016).

59. Schindelin, J. et al. Fiji: an open-source platform for biological-image analysis. Nat. Methods 9, 676-682 (2012).

60. Schneider, C. A., Rasband, W. S. \& Eliceiri, K. W. NIH Image to ImageJ: 25 years of image analysis. Nat. Methods 9, 671-675 (2012).

61. Lazic, S. E. The problem of pseudoreplication in neuroscientific studies: is it affecting your analysis? BMC Neurosci. 11, 5 (2010).

\section{Acknowledgements}

The authors thank Ilona Kamer for excellent technical assistance with blood pressure recordings, Brigitte Sturm for technical assistance with renin RIA and the staff of the MDC Animal Phenotyping Facility for electrolyte measurements. The authors are indebted to Dr. Thomas Jentsch for providing a Clcn2 $2^{+l-}$ mouse ${ }^{29}$. This work was supported by grants from the Ministerium für Kultur und Wissenschaft der Landes Nordrhein-Westfalen (Rückkehrprogramm and Junges Kolleg, both to UIS), the Stif tung Charité (BIH Johanna Quandt Professorship, to UIS), the Deutsche Forschungsgemeinschaft (SCHO 1386/2-1 to UIS, SCHO 1386/3-1 to UIS, SFB 1365 to SF, DNM and UIS), the Fritz Thyssen Stiftung (10.16.1.027MN to UIS) and by a grant to GS by the Deutsche Forschungsgemeinschaft (STO 1260/1-1).

\section{Author contributions}

U.I.S., Ch.F., J.S., and G.S. conceived the study; J.S. and E.S. performed genotyping, organ harvests, stainings, in situ hybridization, immunohistochemistry, real-time PCR and aldosterone ELISA; L.M., S.F., and D.M. performed and analyzed invasive blood pressure monitoring; J.P. contributed renin RIA; G.S. performed and analyzed intracellular calcium recordings; J.S., G.S., and U.I.S. wrote the manuscript, with contributions from all authors.

\section{Competing interests}

Heinrich Heine University Düsseldorf has filed a patent application: EP17209972, Diagnosis and Therapy of Primary Aldosteronism, listing UIS as an inventor. The other authors declare no competing interests.

\section{Additional information}

Supplementary Information accompanies this paper at https://doi.org/10.1038/s41467019-13033-4.

Correspondence and requests for materials should be addressed to U.S.

Reprints and permission information is available at http://www.nature.com/reprints

Peer Review Information Nature Communications thanks the anonymous reviewers for their contribution to the peer review of this work.

Publisher's note Springer Nature remains neutral with regard to jurisdictional claims in published maps and institutional affiliations.

(c) (i) Open Access This article is licensed under a Creative Commons Attribution 4.0 International License, which permits use, sharing, adaptation, distribution and reproduction in any medium or format, as long as you give appropriate credit to the original author(s) and the source, provide a link to the Creative Commons license, and indicate if changes were made. The images or other third party material in this article are included in the article's Creative Commons license, unless indicated otherwise in a credit line to the material. If material is not included in the article's Creative Commons license and your intended use is not permitted by statutory regulation or exceeds the permitted use, you will need to obtain permission directly from the copyright holder. To view a copy of this license, visit http://creativecommons.org/ licenses/by/4.0/.

(c) The Author(s) 2019, corrected publication 2022 